\title{
Spectroscopic characteristics of the cyanomethyl anion and its deuterated derivatives ${ }^{\star}$
}

\author{
Liton Majumdar $^{1}$, Ankan Das ${ }^{1}$, and Sandip K. Chakrabarti ${ }^{2,1}$ \\ ${ }^{1}$ Indian Centre for Space Physics, Chalantika 43, Garia Station Rd., 700084 Kolkata, India \\ e-mail: [ankan;liton]@csp.res.in \\ 2 S. N. Bose National Centre for Basic Sciences, Salt Lake, 700098 Kolkata, India \\ e-mail: chakraba@bose.res.in
}

Received 12 August 2013 / Accepted 17 November 2013

\section{ABSTRACT}

\begin{abstract}
Context. It has long been suggested that $\mathrm{CH}_{2} \mathrm{CN}^{-}$(cyanomethyl anion) might be a carrier of one of the many poorly characterized diffuse interstellar bands. In this paper, our aim is to study various forms (ionic, neutral, and deuterated isotopomer) of $\mathrm{CH}_{2} \mathrm{CN}$ (cyanomethyl radical) in the interstellar medium.

Aims. The aim of this paper is to predict spectroscopic characteristics of various forms of $\mathrm{CH}_{2} \mathrm{CN}$ and its deuterated derivatives. Moreover, we would like to model the interstellar chemistry for predicting the column densities of such species around dark cloud conditions.

Methods. We performed detailed quantum chemical simulations to present the spectral properties (infrared, electronic, and rotational) of various forms of the cyanomethyl radical. Moller-Plesset perturbation theory along with the triple-zeta, correlation-consistent basis set is used to obtain different spectroscopic constants of $\mathrm{CH}_{2} \mathrm{CN}^{-}, \mathrm{CHDCN}^{-}$, and $\mathrm{CD}_{2} \mathrm{CN}^{-}$in the gas phase. They are essential for predicting rotational spectra of these species. Depending on the total number of electrons, there are several allowed spin states for various forms of the cyanomethyl radical. We performed quantum chemical calculations to find out, energetically, the stablest spin states for these species. We computed IR and electronic absorption spectra for different forms of $\mathrm{CH}_{2} \mathrm{CN}$. Moreover, we have also implemented a large gas-grain chemical network to predict the column densities of various forms of the cyanomethyl radical and its related species. To mimic physical conditions around a dense cloud region, the variation in the visual extinction parameters were considered with respect to the hydrogen number density of the simulated cloud.

Results. Our quantum chemical calculation reveals that the singlet spin state is the stablest form of cyanomethyl anion and its deuterated forms. For confirming the detection of the cyanomethyl anion and its two deuterated forms, namely $\mathrm{CHDCN}^{-}$and $\mathrm{CD}_{2} \mathrm{CN}^{-}$, we present the rotational spectral information of these species in the Appendix. Our chemical model predicts that the deuterated forms of cyanomethyl radicals (especially the anions) are also reasonably abundant around the dense region of the molecular cloud.
\end{abstract}

Key words. astrochemistry - methods: numerical - ISM: abundances - ISM: clouds - ISM: molecules - radio lines: ISM

\section{Introduction}

In the past years, several works have investigated the formation of complex molecules in and around cold interstellar clouds (Hasegawa \& Herbst 1993; Hasegawa et al. 1992; Majumdar et al. 2012, 2013; Das et al. 2013a). To date, more than 170 molecules have been observed in interstellar mediums (ISMs) or circumstellar shells. It is now well known that to model the formation of complex molecules in ISMs, the interstellar grain chemistry has to be an integral part of the chemical evolutionary path (Stantcheva et al. 2002; Chakrabarti et al. 2006a,b; Das et al. 2008b, 2010; Das \& Chakrabarti 2011; Cuppen \& Herbst 2007; Cuppen et al. 2009).

One of the stumbling blocks in spectroscopy in an astronomical context is the lack of adequate knowledge of the origin of unidentified diffuse interstellar bands (DIBs). These DIBs are basically a series of absorption lines that are observed toward just about every star in our galaxy that has interstellar material in front of it. Herbig (1995) and Sarre (2006) have reviewed the very long-standing problem of the diffuse interstellar bands.

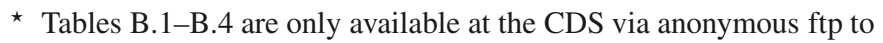
cdsarc.u-strasbg. fr (130.79.128.5) or via http://cdsarc.u-strasbg.fr/viz-bin/qcat?]/A+A/562/A56
They pointed out that some organic molecules could be the possible candidates for more than 300 DIBs in the ISM. According to Sarre (2000), some (possibly many) of the DIBs are due to electronic transitions between the ground and the dipole bound states of negatively charged polar molecules or small polar grains. Sarre (2000) also first pointed out that $\mathrm{CH}_{2} \mathrm{CN}^{-}$might be a carrier of the DIBs. A follow-up study by Cordiner \& Sarre (2007) explored the possibility of $\mathrm{CH}_{2} \mathrm{CN}^{-}$as a possible carrier of the narrow DIB at $8037 \pm 0.15 \AA$.

The cyanomethyl radical $\left(\mathrm{CH}_{2} \mathrm{CN}\right)$ is the simplest cyanide derivative of the methyl radical $\left(\mathrm{CH}_{3}\right)$. The presence of a cyano group in the molecule means that a dipole moment is generated, which makes it possible to search for the $\mathrm{CH}_{2} \mathrm{CN}$ radical by electric-dipole allowed microwave transitions. According to Herbst (2001), an appreciable amount of $\mathrm{CH}_{3}$ radical is expected in the diffuse and dense molecular clouds. The first detection of $\mathrm{CH}_{2} \mathrm{CN}$ was reported by Irvine et al. (1988) in two of the best characterized molecular clouds, namely, TMC-1 and Sgr B2. Their work was based on the observations performed using the decommissioned $14 \mathrm{~m}$ antenna at the Five College Radio Astronomy Observatory, the $43 \mathrm{~m}$ antenna at NRAO's Green Bank facility, the $20 \mathrm{~m}$ antenna at Onsala Space Observatory, and the $45 \mathrm{~m}$ antenna at Nobeyama Radio Observatory. A few 
years ago, the observed spectra was verified experimentally in the laboratory by Ozeki et al. (2004), using a Fourier-transform microwave spectrometer in combination with a pulsed-discharge nozzle. The first detection of $\mathrm{CH}_{2} \mathrm{CN}$ in IRC +10216 was reported by Agundez et al. (2008).

Lykke et al. (1987) employed the auto-detachment spectroscopy technique to study the dynamics of $\mathrm{CH}_{2} \mathrm{CN}^{-}$and one of its deuterated isotopomers, namely, $\mathrm{CD}_{2} \mathrm{CN}^{-}$. In their work, dynamics of the auto-detachment process was studied and various mechanisms for detachment were described. Cordiner \& Sarre (2007) used the rotational constants obtained by Lykke et al. (1987) to compute the absorption spectrum arising from the ${ }^{1} B_{1}-\tilde{\mathrm{X}}^{1} \mathrm{~A}^{\prime}$ transition of $\mathrm{CH}_{2} \mathrm{CN}^{-}$for $\mathrm{CH}_{2} \mathrm{CN}^{-}$in equilibrium with $\mathrm{CMB}$ at $2.74 \mathrm{~K}$. According to their calculation, if $\mathrm{CH}_{2} \mathrm{CN}^{-}$ is present in the ISM with an ortho to para abundance ratio of 3:1, ${ }^{1} B_{1}-\tilde{X}^{1} \AA$ transitions having $K_{a}^{\prime \prime}=1$ would produce strong spectral features at $8024.8 \AA$ and $8049.6 \AA$. However, these features are absent in the interstellar spectra. According to them this could not be treated as granted, though the $\lambda 8037$ DIB and transition of $\mathrm{CH}_{2} \mathrm{CN}^{-}$is consistent. Further study regarding the $\mathrm{CH}_{2} \mathrm{CN}^{-}$is essential for making such strong assignments. Fortenberry \& Crawford (2011a) carried out quantum chemical calculations for predicting new dipole-bound singlet states for anions of interstellar interest. Fortenberry et al. (2013) used quartic force fields and second-order vibrational perturbation theory to calculate the appropriate spectroscopic constants and fundamental vibrational frequencies for $\tilde{\mathrm{X}}^{1} \mathrm{~A}^{\prime} \mathrm{CH}_{2} \mathrm{CN}^{-}$to facilitate its confirmed detection.

According to Park \& Woon (2006), ions embedded in icy grain mantles are thought to account for various observed infrared spectroscopic features, particularly in certain young stellar objects like W33A. Observations of different interstellar molecules $\left(\mathrm{CH}_{3} \mathrm{OH}, \mathrm{HCOOH}, \mathrm{NH}_{3}, \mathrm{H}_{2} \mathrm{O}, \mathrm{CO}, \mathrm{CO}_{2}, \mathrm{CH}_{4}\right.$, $\mathrm{H}_{2} \mathrm{CO}$, OCS, etc.) by Gibb et al. (2000), anions $\left(\mathrm{OCN}^{-}\right.$, $\mathrm{HCOO}^{-}$) by Soifer et al. (1979) and Schutte et al. (1997, 1999), cations $\left(\mathrm{HCO}^{+}, \mathrm{NH}_{4}^{+}\right)$by Schutte \& Greenberg (1997), Demyk et al. (1998), Hudson et al. (2001), Novozamsky et al. (2001) motivated us to consider the spectroscopy of different forms (neutral, cationic, and anionic) of $\mathrm{CH}_{2} \mathrm{CN}$ embedded in icy grain mantles. According to Park \& Woon (2006), quantum chemical approach along with a continuum model is well suited to modeling the spectroscopic properties of molecules and ions embedded within amorphous ice matrices. Inspired by these studies, we performed a detail spectroscopy as well as astrochemical modeling of different forms of $\mathrm{CH}_{2} \mathrm{CN}$. We expect that our study would illuminate the possibility of finding other forms of $\mathrm{CH}_{2} \mathrm{CN}$ in and around ISMs.

The plan of this paper is the following. In Sect. 2, method and computational details for the purpose of spectroscopy of $\mathrm{CH}_{2} \mathrm{CN}$ and its related molecules are discussed. Different computational results are presented in Sect. 3. In Sect. 4, we draw our conclusion. In Appendix A, we discuss the chemical modeling and results. Moreover, in the Appendix B, we have included four tables for presenting different vibrational (Table B.1) and rotational transitions (Tables B.2-B.4).

\section{Methods and computational details}

\subsection{Quantum chemical simulation and spectroscopy}

Recent work by Huang \& Lee (2008) suggests that the quantum chemical computational tools could be very useful for obtaining rotational constants often within an accuracy of $20 \mathrm{MHz}$ (especially for the B-type and C-type constants). Vibrational frequencies accurate to $5 \mathrm{~cm}^{-1}$ or better could be obtained from the quantum chemical calculations (Huang \& Lee 2008, 2009, 2011; Huang et al. 2011; Inostroza et al. 2011; Fortenberry \& Crawford 2011a,b,c; Fortenberry et al. 2012a,b, 2013). Motivated by these works, we perform a detailed quantum chemical simulation to report various spectral aspects of different forms of $\mathrm{CH}_{2} \mathrm{CN}$ molecule in the vibrational (harmonic), electronic, and rotational modes.

All the computations on neutral $\mathrm{CH}_{2} \mathrm{CN}$ were performed by using spin-unrestricted (UHF) wave functions, while computations of the closed-shell anions used spin-restricted (RHF) wave functions. First, the geometries of the neutral and ionic forms of $\mathrm{CH}_{2} \mathrm{CN}$ are optimized at the Becke three-parameter Exchange and at the Lee, Yang and Parr correlation functional (B3LYP) with $6-311++\mathrm{G}$ as the basis set. B3LYP is the most popular DFT model. This method is termed as a hybrid method, because it uses corrections for both gradient and exchange correlations. Becke three parameter hybrid functional forms were devised by Becke (1993) along with the non-local correlation provided by LYP (Lee et al. 1988). Dipole moments of all of these species are computed by using the same level of theory. For computing dipole moments, we considered the center of mass to be our standard origin in the Gaussian $09 \mathrm{~W}$ program (Frisch et al. 2009). Gas-phase vibrational frequencies of these species were obtained from the minimum energy structure at the same level of theory. Our computed vibrational frequencies are harmonic in nature since the Gaussian $09 \mathrm{~W}$ program computes these frequencies based on the harmonic oscillator approximation. To find out the harmonic vibrational frequencies of these species in the ice phase, we also optimized these geometries in B3LYP/6$311++$ G level using the SCRF method. The SCRF method in the Gaussian 09W program is used to perform calculations in presence of a solvent by placing the solute in a cavity within a solvent reaction field. The Polarizable Continuum Model (PCM) using the integral equation formalism variant (IEFPCM) is the default SCRF method. This method creates the solute cavity via a set of overlapping spheres. It was initially devised by Tomasi and coworkers and Pascual-Ahuir and co-workers (Tomasi et al. 2002, 2005, 1999; Pascual-Ahuir et al. 1994). The electronic absorption spectra of these species are also obtained using the higher order method (EOM-CCSD) with the basis set aug-cc-pVDZ. This method use coupled cluster for the description of excited states using the equation of motion approach. Depending on the total number of electrons of a species, we vary the spin multiplicities to locate the most reasonable spin state. To get more accurate information about the rotational spectral parameters (rotational \& distortional constants), we used MP2/aug-cc-pVTZ level of theory in the symmetrically, as well as the asymmetrically reduced Hamiltonian. Rotational motion of a molecule in Gaussian 09W program commonly starts from the rigid rotor model, which assumes that the molecule is rigid. For our calculation, we have to know the structure of the molecule and from that we could get the moment of inertia, which could then be utilized to obtain the eigenvalues. Generally, this requires a very good estimation of the structure and optimization of a molecule. In an earlier paper (Das et al. 2013), we carried out a similar type of calculation for HCOCN, where we implemented the MP2/augcc-pVTZ level of theory and showed that this level of theory produced results in good agreement with the experiment. For computing vibrationally averaged structures, the corrections for the interactions between rotation and vibration are important. We computed these vibrational-rotational coupling by the Gaussian 09W program. Further corrections for vibrational averaging and anharmonic corrections to the vibration are also implemented by 
Table 1. Relative energies (eV) of different forms of $\mathrm{CH}_{2} \mathrm{CN}$ (neutral, cationic, and anionic) in the gas phase and the ice phase along with their dipole moments.

\begin{tabular}{|c|c|c|c|c|c|}
\hline Species & Spin state & $\begin{array}{l}\text { Relative energy in gas phase } \\
\text { (in eV) }\end{array}$ & $\begin{array}{l}\text { Dipole moments in gas phase } \\
\text { (in Debye) }\end{array}$ & $\begin{array}{l}\text { Relative energy in ice phase } \\
\text { (in eV) }\end{array}$ & $\begin{array}{l}\text { Dipole moments in ice phase } \\
\text { (in Debye) }\end{array}$ \\
\hline \multirow{3}{*}{$\mathrm{CH}_{2} \mathrm{CN}$} & doublet & 0 & 3.5974 & 0 & 4.6355 \\
\hline & quartet & 4.08 & 2.4705 & 4.15 & 3.3207 \\
\hline & sextet & 8.16 & 1.5430 & 8.28 & 1.8471 \\
\hline \multirow{3}{*}{$\mathrm{CH}_{2} \mathrm{CN}^{+}$} & singlet & 0 & 5.305 & 0 & 6.606 \\
\hline & triplet & 1.94 & 3.802 & 2.08 & 4.474 \\
\hline & quintet & 5.47 & 3.653 & 5.63 & 4.213 \\
\hline \multirow{3}{*}{$\mathrm{CH}_{2} \mathrm{CN}^{-}$} & singlet & 0 & 1.212 & 0 & 2.469 \\
\hline & triplet & 2.06 & 6.712 & 3.17 & 3.183 \\
\hline & quintet & 6.35 & 6.5460 & 6.52 & 2.8671 \\
\hline
\end{tabular}

using the Gaussian 09W program. These rotational and distortional constants are required to predict the spectrum of a particular species. Herb Picket's SPCAT program (Pickett 1991) was designed in such a way that one would get the spectral information by putting the rotational and distortional constants and other relevant parameters according to the prescribed format. In our calculations, rotational and distortional constants were computed from the Gaussian 09W program. These values are then inserted into the SPCAT program to obtain the spectral information of $\mathrm{CH}_{2} \mathrm{CN}^{-}, \mathrm{CHDCN}^{-}$, and $\mathrm{CD}_{2} \mathrm{CN}^{-}$.

\section{Results and discussion}

\subsection{Chemical parameters}

The way the energy of a molecular system varies with small changes in its structure is specified by its potential energy surface. In this work, the geometry optimization of different forms of $\mathrm{CH}_{2} \mathrm{CN}$ (neutral, ionic, and its isotopomers) was performed to locate the minima on the potential energy surface, thereby predicting the equilibrium structure of these molecules. At the minima, the first derivative of the energy (i.e., the energy gradient) is zero and thus the forces are also zero. It is customary to know energetically the most stable form of $\mathrm{CH}_{2} \mathrm{CN}$ that can exist in and around the ISM. In Table 1, we provide the relative energies of the different spin states of the gas/ice phase $\mathrm{CH}_{2} \mathrm{CN}$, $\mathrm{CH}_{2} \mathrm{CN}^{+}$, and $\mathrm{CH}_{2} \mathrm{CN}^{-}$in $\mathrm{eV}$ unit and their dipole moments in Debye units. Dipole moments of all the species are computed by considering the center of mass as our standard origin. For the neutral $\mathrm{CH}_{2} \mathrm{CN}$, the total number of electrons are 21. Because it is an odd number, the allowed spin states are doublet, quartet, sextet, etc. By performing the geometry optimization and energy calculation at B3LYP/6-311++G level of theory, we found that the doublet spin state of neutral $\mathrm{CH}_{2} \mathrm{CN}$ is most stable. Relative energies of the quartet and sextet spin states of $\mathrm{CH}_{2} \mathrm{CN}$ with respect to its minimum energy spin state (doublet) are found to be $4.08 \mathrm{eV}$ and $8.16 \mathrm{eV}$, respectively. The mono-cationic form of $\mathrm{CH}_{2} \mathrm{CN}\left(\mathrm{CH}_{2} \mathrm{CN}^{+}\right)$is an even electron system that corresponds to its having the singlet, triplet, quintet, etc. as the allowed spin states. Among these allowed spin states, the singlet spin state is found to be the stablest spin state for $\mathrm{CH}_{2} \mathrm{CN}^{+}$. Relative energies of the triplet and quintet spin states of $\mathrm{CH}_{2} \mathrm{CN}^{+}$with respect to its minimum energy spin state (singlet) are found to be $1.94 \mathrm{eV}$ and $5.47 \mathrm{eV}$, respectively. The cyanomethyl anion also has an even electron system having singlet, triplet, quintet etc. as the allowed spin states. The singlet spin state of $\mathrm{CH}_{2} \mathrm{CN}^{-}$is found to be stablest spin state. Relative energies of the triplet and quintet spin states of $\mathrm{CH}_{2} \mathrm{CN}^{-}$with respect to its minimum energy spin state (singlet) are found to be $2.06 \mathrm{eV}$ and $6.35 \mathrm{eV}$ respectively. In Table 1, the relative energies of different spin states of neutral $\mathrm{CH}_{2} \mathrm{CN}, \mathrm{CH}_{2} \mathrm{CN}^{+}$and $\mathrm{CH}_{2} \mathrm{CN}^{-}$are shown along with their respective dipole moments.

These molecules could also be trapped in the interstellar ice, so it is also necessary to identify the most stable configuration of the various forms of $\mathrm{CH}_{2} \mathrm{CN}$ in the interstellar grain. For this purpose, we considered the self-consistent reaction field method, which considers the solvent (ice) as a continuum of uniform dielectric constant, and the solute (different forms of $\mathrm{CH}_{2} \mathrm{CN}$ ) is placed into a cavity within the solvent. In the ice phase, it has been found that the doublet $\mathrm{CH}_{2} \mathrm{CN}$ (dipole moment $=4.6355$ Debye), singlet $\mathrm{CH}_{2} \mathrm{CN}^{+}$(dipole moment $=6.606$ Debye) and singlet $\mathrm{CH}_{2} \mathrm{CN}^{-}$(dipole moment $=2.469$ Debye) are the most stable configurations in the ice phase. Among the deuterated forms, doublet $\mathrm{CD}_{2} \mathrm{CN}$, singlet $\mathrm{CD}_{2} \mathrm{CN}^{+}$, singlet $\mathrm{CD}_{2} \mathrm{CN}^{-}$, doublet $\mathrm{CHDCN}$, singlet $\mathrm{CHDCN}^{+}$, and singlet $\mathrm{CHDCN}^{-}$are the stablest configurations in the ice phase.

\subsection{Astronomical spectroscopy}

\subsubsection{Vibrational spectroscopy}

To study the spectral properties (vibrational) for various forms of $\mathrm{CH}_{2} \mathrm{CN}$, we need to compute the infrared peak positions with their absorbance in the gas phase and in other astrophysical environments. As discussed in Sect. 3.1, the spin multiplicity varies depending on the total electron content of the system. In the present work, we have considered that the neutral, monocationic and mono-anionic forms of $\mathrm{CH}_{2} \mathrm{CN}$ are possible in the ISM. For each of these states, we considered three different spin states.

In Table B.1, we present vibrational frequencies (harmonic) of $\mathrm{CH}_{2} \mathrm{CN}$ with its different charge and spin states for the gas phase and the ice phase. Observational evidences suggest that ice could be mixed in nature. A major contributor to interstellar ice is $\mathrm{H}_{2} \mathrm{O}$, but carbon monoxide and methanol also contribute significantly (Keane et al. 2001; Das \& Chakrabarti, 2011). Since $\mathrm{H}_{2} \mathrm{O}$ is the major constituent $(>70 \%)$ of the interstellar ice, we considere only the water ice for our simulation. For the pure water ice, Gaussian $09 \mathrm{~W}$ uses a dielectric constant of $\sim 78.5$ by default. We note that the most intense peak, as well as other peaks for almost all forms of $\mathrm{CH}_{2} \mathrm{CN}$ in the gas phase is shifted in the ice phase (Table B.1). Isotopic effects on the spectral shifts are caused by differences in vibrational modes (harmonic) due to different isotopic masses. In our chemical model, we have considered two types of isotopomer of $\mathrm{CH}_{2} \mathrm{CN}$, namely $\mathrm{CHDCN}$ and $\mathrm{CD}_{2} \mathrm{CN}$. They have different infrared spectra because the 


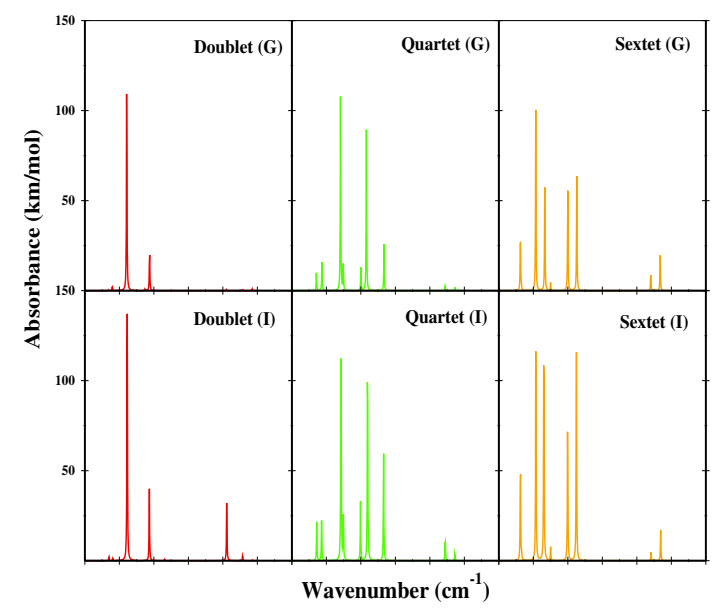

Fig. 1. Infrared spectrum of different forms of $\mathrm{CD}_{2} \mathrm{CN}$ in gas phase, ice phase, and mixed ice.

substitution of isotope changes the reduced mass of the corresponding molecule. In this case also, we find that the most intense mode, as well as the other modes of $\mathrm{CHDCN}$ and $\mathrm{CD}_{2} \mathrm{CN}$ in the gas phase is shifted in the ice phase. Infrared peak positions of $\mathrm{CHDCN}$ and $\mathrm{CD}_{2} \mathrm{CN}$ with their absorbance in the gas phase as well as in other astrophysical environments are shown in Table B.1. The high value of the absorbance in Table B.1 implies the most probable transitions. According to Person \& Kubulat (1990), one of the most challenging problems in the study of infrared spectroscopy is to understand the intensity of absorption by the different fundamental modes of vibration in the infrared spectrum of a molecule. Magnitudes of the integrated molar absorption coefficients are calculated by;

$A=\frac{1}{100 C l} \int \ln \left(I_{0} / I\right) \mathrm{d} v$.

Depending on the mode of vibration and the molecule involved, the value of the absorption coefficients could vary from $0-10^{4} \mathrm{~km} / \mathrm{mol}$. Here, $C$ is the concentration in $\mathrm{mol}^{-1}, l$ the path length in $\mathrm{cm}, I_{0}$ the intensity of the light incident, $I$ the intensity of light transmitted, and $v$ the wavenumber in $\mathrm{cm}^{-1}$. The factor of 100 converts the values to $\mathrm{km} / \mathrm{mol}$, with the resulting convenient range of possible values. The integration is taken over the entire absorption band. From our relative energy calculation, it is clear that the singlet state of $\mathrm{CH}_{2} \mathrm{CN}^{-}, \mathrm{CHDCN}^{-}$, and $\mathrm{CD}_{2} \mathrm{CN}^{-}$is the stablest spin state. From Table B.1 it is evident that in the case of gas phase $\mathrm{CH}_{2} \mathrm{CN}^{-}$(singlet), the transition at $2056.73 \mathrm{~cm}^{-1}$ is the strongest one. In the ice phase, the strongest transition for $\mathrm{CH}_{2} \mathrm{CN}^{-}$(singlet) turns out to be at $2016.35 \mathrm{~cm}^{-1}$. Transitions at $2053.96 \mathrm{~cm}^{-1}$ and $2013.34 \mathrm{~cm}^{-1}$ are the most probable ones for $\mathrm{CHDCN}^{-}$(singlet) in the gas phase and ice phase respectively. In case of $\mathrm{CD}_{2} \mathrm{CN}^{-}$(singlet), transition at $2050.23 \mathrm{~cm}^{-1}$ and $2009.48 \mathrm{~cm}^{-1}$ are the most probable ones in the gas and ice phases, respectively. To have some idea about the accuracy of our computed harmonic vibrational frequencies, we compared our result for the singlet state of $\mathrm{CH}_{2} \mathrm{CN}^{-}$with that of the Fortenberry et al. (2013) in Table B.1. Our results appear to be reasonable.

In Fig. 1, we have shown how the isotopic substitution $\left(\mathrm{CD}_{2} \mathrm{CN}\right)$ as well as spin multiplicity plays a part in the vibrational (harmonic) progressions of $\mathrm{CH}_{2} \mathrm{CN}$ in the gas (denoted by $\mathrm{G}$ in Fig. 1), ice (denoted by I in Fig. 1). The " $Y$ axis" of Fig. 1 represent the absorbance (in $\mathrm{km} / \mathrm{mol}$ ) and the " $X$ axis" represent the wavenumber $\left(\right.$ in $\left.\mathrm{cm}^{-1}\right)$.

\subsubsection{Rotational spectroscopy}

In Table 2, we have summarized our calculated rotational and distortional constants, along with other spectroscopic constants for only stable spin state of $\mathrm{CH}_{2} \mathrm{CN}^{-}, \mathrm{CHDCN}^{-}$, and $\mathrm{CD}_{2} \mathrm{CN}^{-}$. To estimate about the accuracy of our model, we compared our results with those from other existing theoretical and experimental works. Fortenberry et al. (2013) report theoretically computed rotational and distortional constants along with other spectroscopic constants. They used CCSD(T)/aug-cc-pVQZ level of theory for this computation. For the computing anharmonic frequencies, an analytic second derivative of energies at displaced geometries required. But the $\operatorname{CCSD}(\mathrm{T})$ method in the Gaussian 09W program only implements energies, so analytic second derivative of energies are not available at this level of theory, so it is not possible to compute the rotational and distortional constants at the CCSD(T)/aug-cc-pVQZ level of theory as used by Fortenberry et al. (2013) using the Gaussian 09W program. In our calculation, we computed the rotational and distortional constants at MP2/aug-cc-pVTZ level of theory. In Table 2, we also compared our results with the experimental results of Lykke et al. (1987), who carried out the auto-detachment spectroscopy technique to study the dynamics of $\mathrm{CH}_{2} \mathrm{CN}^{-}$and one of its deuterated isotopomer $\left(\mathrm{CD}_{2} \mathrm{CN}^{-}\right)$. They also report the rotational and distortional constants of $\mathrm{CH}_{2} \mathrm{CN}^{-}$and $\mathrm{CD}_{2} \mathrm{CN}^{-}$. From Table 2, it is clear that our results are in close agreement with theoretical and experimental work. This leads us to believe that our computed parameters for the deuterated isotopomers of $\mathrm{CH}_{2} \mathrm{CN}^{-}$could be useful for further astronomical investigation of these molecules.

To summarize the results of our computation on rotational spectroscopy, we prepared our spectral information for $\mathrm{CH}_{2} \mathrm{CN}^{-}, \mathrm{CHDCN}^{-}$, and $\mathrm{CD}_{2} \mathrm{CN}^{-}$. In Tables $\mathrm{B} 2-\mathrm{B} 4$, the computed rotational transitions for the gas phase $\mathrm{CH}_{2} \mathrm{CN}^{-}$, $\mathrm{CHDCN}^{-}$, and $\mathrm{CD}_{2} \mathrm{CN}^{-}$are shown. Tables B2 and $\mathrm{B} 4$ contain the data for $\mathrm{CH}_{2} \mathrm{CN}^{-}$, and $\mathrm{CD}_{2} \mathrm{CN}^{-}$respectively. These tables are prepared with the experimental constants (Lykke et al. 1987) given in Table 2. Here, errors on the computed line frequencies are related to the errors on the constants given in Table 2. Lykke et al. (1987) reported the rotational and distortional constants for $\mathrm{CH}_{2} \mathrm{CN}^{-}$and $\mathrm{CD}_{2} \mathrm{CN}^{-}$by fitting the observed experimental transitions with the Watson S-reduced Hamiltonian using a least square routine. Our reported spectroscopic constants are in symmetrically reduced Hamiltonian, and they can be computed with the Gaussian $09 \mathrm{~W}$ program by considering anharmonic vibration-rotation coupling via perturbation theory. By following Lykke et al. (1987), in Table 2, we tabulated the values of $1 \sigma$ in units of $\mathrm{MHz}$ in the parentheses of the corresponding experimental constants. The quantity $\sigma$ corresponds to the standard deviation of the fit to the entire band. Armed with these values, we have prepared Tables B2 and B4 to report the rotational transitions of $\mathrm{CH}_{2} \mathrm{CN}^{-}$and $\mathrm{CD}_{2} \mathrm{CN}^{-}$respectively. Expected errors on any line frequencies are clearly mentioned in the captions of Tables B.2 and B.4. In the case of Table B.2, for the line frequencies $19-319 \mathrm{GHz}$, there could be errors between $\pm 1-20 \mathrm{MHz}\left(\mathrm{d} v / v=6.16 \times 10^{-5}\right.$ for any line frequency). Similarly for Table B.4, for the transitions between 18-314 GHz, there could be errors between $\pm 0.6-12 \mathrm{MHz}$ $\left(\mathrm{d} v / v=3.77 \times 10^{-5}\right)$. Since, until now, there are no experimental constants reported for the $\mathrm{CHDCN}^{-}$, in Table B.3, we give the information regarding the rotational transitions for $\mathrm{CHDCN}^{-}$ by using our calculated rotational and distortional constants (Table 2). Tables B.2-B.4 were prepared by selecting only those transitions that have intensities beyond $10^{-7} \mathrm{~nm}^{2} \mathrm{MHz}$ 
Table 2. Different spectroscopical constants of $\mathrm{CH}_{2} \mathrm{CN}^{-}, \mathrm{CHDCN}^{-}$, and $\mathrm{CD}_{2} \mathrm{CN}^{-}$in gas phase at MP2/aug-cc-pVTZ level of theory.

\begin{tabular}{|c|c|c|c|c|}
\hline Species & Constants & $\begin{array}{c}\text { Theoretical values in } \mathrm{MHz} \\
\text { by Fortenberry et al. (2013) } \\
\text { at CCSD(T)/aug-cc-pVQZ level of theory }\end{array}$ & $\begin{array}{c}\text { Experimental values in } \mathrm{MHz} \\
\text { (Lykke et al. (1987) }\end{array}$ & Our calculated values in $\mathrm{MHz}$ \\
\hline $\mathrm{CH}_{2} \mathrm{CN}^{-}$ & $\begin{array}{c}\mathrm{A}_{0} \\
\mathrm{~B}_{0} \\
\mathrm{C}_{0} \\
\mathrm{~A}_{e} \\
\mathrm{~B}_{e} \\
\mathrm{C}_{e} \\
\tau_{\text {aaaa }}^{\prime} \\
\tau_{\text {bbbb }}^{\prime} \\
\tau_{\text {cccc }}^{\prime} \\
\tau_{\text {abb }}^{\prime} \\
\tau_{\text {aacc }}^{\prime} \\
\tau_{\text {bbcc }}^{\prime} \\
\mathrm{D}_{J} \\
\mathrm{D}_{J K} \\
\mathrm{D}_{K} \\
\mathrm{~d}_{1} \\
\mathrm{~d}_{2} \\
\end{array}$ & $\begin{array}{c}233945.4 \\
10823.22 \\
10386.01 \\
230904.9 \\
10849.79 \\
10445.37 \\
-100.708 \\
-0.020 \\
-0.017 \\
-1.812 \\
0.043 \\
-0.018 \\
0.005 \\
0.434 \\
24.739 \\
0.000 \\
0.000 \\
\end{array}$ & $\begin{array}{c}278636.4( \pm 4.197095) \\
10145.79( \pm 0.599585) \\
9805.043( \pm 0.629564) \\
- \\
- \\
- \\
- \\
- \\
- \\
- \\
- \\
- \\
0.0049465( \pm 0.00029979) \\
0.3888308( \pm 0.00449689) \\
30.06319( \pm 0.06295642) \\
-0.0002698( \pm 0.00005396) \\
-0.000175678( \pm 0.00002308)\end{array}$ & $\begin{array}{c}298584.615 \\
10069.925 \\
9687.183 \\
287675.631 \\
10086.765 \\
9745.074 \\
-87.6704 \\
-0.0155 \\
-0.013 \\
-1.540 \\
-0.01594 \\
-0.01436 \\
0.0035 \\
0.3823 \\
21.531 \\
-0.0001297 \\
-0.000032387 \\
\end{array}$ \\
\hline $\mathrm{CHDCN}^{-}$ & $\begin{array}{c}\mathrm{A}_{0} \\
\mathrm{~B}_{0} \\
\mathrm{C}_{0} \\
\mathrm{~A}_{e} \\
\mathrm{~B}_{e} \\
\mathrm{C}_{e} \\
\tau_{\text {aaaa }}^{\prime} \\
\tau_{\text {bbbb }}^{\prime} \\
\tau_{\text {cccc }}^{\prime} \\
\tau_{\text {aabb }}^{\prime} \\
\tau_{\text {aacc }}^{\prime} \\
\tau_{\text {bbcc }}^{\prime} \\
\mathrm{D}_{J} \\
\mathrm{D}_{J K} \\
\mathrm{D}_{K} \\
\mathrm{~d}_{1} \\
\mathrm{~d}_{2} \\
\end{array}$ & $\begin{array}{l}- \\
- \\
- \\
- \\
- \\
- \\
- \\
- \\
- \\
- \\
- \\
- \\
- \\
- \\
- \\
- \\
-\end{array}$ & $\begin{array}{l}- \\
- \\
- \\
- \\
- \\
- \\
- \\
- \\
- \\
- \\
- \\
- \\
- \\
- \\
- \\
- \\
- \\
\end{array}$ & $\begin{array}{c}203788.893 \\
9432.261 \\
8960.774 \\
197655.384 \\
9454.839 \\
9023.214 \\
-52.524 \\
-0.0144 \\
-0.0115 \\
-1.268 \\
0.0469 \\
-0.0128 \\
0.0031 \\
0.2994 \\
12.828 \\
-0.0001804 \\
-0.00005339 \\
\end{array}$ \\
\hline $\mathrm{CD}_{2} \mathrm{CN}^{-}$ & $\begin{array}{c}\mathrm{A}_{0} \\
\mathrm{~B}_{0} \\
\mathrm{C}_{0} \\
\mathrm{~A}_{e} \\
\mathrm{~B}_{e} \\
\mathrm{C}_{e} \\
\tau_{\text {aaaa }}^{\prime} \\
\tau_{\text {bbbb }}^{\prime} \\
\tau_{\text {cbcc }}^{\prime} \\
\tau_{\text {aabb }}^{\prime} \\
\tau_{\text {aacc }}^{\prime} \\
\tau_{\text {bbcc }}^{\prime} \\
\mathrm{D}_{J} \\
\mathrm{D}_{J K} \\
\mathrm{D}_{K} \\
\mathrm{~d}_{1} \\
\mathrm{~d}_{2} \\
\end{array}$ & $\begin{array}{l}- \\
- \\
- \\
- \\
- \\
- \\
- \\
- \\
- \\
- \\
- \\
- \\
- \\
- \\
- \\
- \\
-\end{array}$ & $\begin{array}{c}140757.7( \pm 4.496888) \\
9004.927( \pm 0.329772) \\
8487.186( \pm 0.329772) \\
- \\
- \\
- \\
- \\
- \\
- \\
- \\
- \\
- \\
0.003165808( \pm 0.00013191) \\
0.2320094( \pm 0.00233838) \\
7.10808( \pm 0.13190870) \\
-0.0000288( \pm 0.00004797) \\
-0.00008094( \pm 0.00001229)\end{array}$ & $\begin{array}{c}147451.465 \\
8916.168 \\
8353.217 \\
143948.398 \\
8939.687 \\
8416.965 \\
-21.951 \\
-0.0127 \\
-0.00967 \\
-1.0326 \\
0.01407 \\
-0.01096 \\
0.0026 \\
0.2498 \\
5.235 \\
-0.0001928 \\
-0.000070902\end{array}$ \\
\hline
\end{tabular}

Notes. The numbers in the parentheses represent the errors (in MHZ) of the fit to the entire band obtained by Lykke et al. (1987).

(base 10 logarithm of the intensities are tabulated). It is noticed that we have several different entries of greatly differing intensities for the same line frequency. Since the strongest component suffice, here (in Tables B.2-B.4), only the component having the highest intensity for the same line frequency is tabulated.

\subsubsection{Electronic spectroscopy}

$\mathrm{CH}_{2} \mathrm{CN}^{-}$only has one excited state (a second singlet state) in the gas phase. This has been shown experimentally (Lykke et al. 1987) and theoretically (Fortenberry \& Crawford 2011a). Additionally, since the triplet and quintet states of $\mathrm{CH}_{2} \mathrm{CN}^{-}$are 
Table 3. Electronic transitions of the most stable spin state of $\mathrm{CH}_{2} \mathrm{CN}, \mathrm{CH}_{2} \mathrm{CN}^{+}$, and $\mathrm{CH}_{2} \mathrm{CN}^{-}$at EOM-CCSD/aug-cc-pVDZ level of theory in gas phase and water ice phase.

\begin{tabular}{|c|c|c|c|c|c|c|c|c|}
\hline Name \& spin state & $\begin{array}{c}\text { Wavelength } \\
\text { (gas phase) } \\
\text { (in nm) }\end{array}$ & Absorbance & $\begin{array}{l}\text { Oscillator } \\
\text { strength }\end{array}$ & Transitions & $\begin{array}{c}\text { Wavelength } \\
\left(\mathrm{H}_{2} \mathrm{O} \text { ice }\right) \\
(\text { in nm })\end{array}$ & Absorbance & $\begin{array}{c}\text { Oscillator } \\
\text { strength }\end{array}$ & Transitions \\
\hline Doublet $\mathrm{CH}_{2} \mathrm{CN}$ & $\begin{array}{l}237.47 \\
174.07\end{array}$ & $\begin{array}{l}696.35 \\
170.09\end{array}$ & $\begin{array}{l}0.0167 \\
0.0042\end{array}$ & $\begin{array}{l}2-A^{\prime \prime} \rightarrow 2-A^{\prime} \\
2-A^{\prime \prime} \rightarrow 2-A^{\prime}\end{array}$ & $\begin{array}{l}225.57 \\
190.29 \\
142.68 \\
\end{array}$ & $\begin{array}{c}379.59 \\
625.57 \\
28.28 \\
\end{array}$ & $\begin{array}{l}0.0093 \\
0.0133 \\
0.0007 \\
\end{array}$ & $\begin{array}{l}2-\mathrm{B} 1 \rightarrow 2-\mathrm{A} 1 \\
2-\mathrm{B} 1 \rightarrow 2-\mathrm{B} 1 \\
2-\mathrm{B} 1 \rightarrow 2-\mathrm{B} 2\end{array}$ \\
\hline Singlet $\mathrm{CH}_{2} \mathrm{CN}^{+}$ & $\begin{array}{l}267.63 \\
124.44 \\
\end{array}$ & $\begin{array}{l}7762.40 \\
4250.86 \\
\end{array}$ & $\begin{array}{l}0.1793 \\
0.1055 \\
\end{array}$ & $\begin{array}{l}1-\mathrm{A}^{\prime} \rightarrow 1-\mathrm{A}^{\prime} \\
1-\mathrm{A}^{\prime} \rightarrow 1-\mathrm{A}^{\prime}\end{array}$ & $\begin{array}{c}242.6 \\
122.95 \\
\end{array}$ & $\begin{array}{l}6291.27 \\
5423.60 \\
\end{array}$ & $\begin{array}{l}0.1538 \\
0.1346 \\
\end{array}$ & $\begin{array}{l}1-\mathrm{A}^{\prime} \rightarrow 1-\mathrm{A}^{\prime} \\
1-\mathrm{A}^{\prime} \rightarrow 1-\mathrm{A}^{\prime}\end{array}$ \\
\hline Singlet $\mathrm{CH}_{2} \mathrm{CN}^{-}$ & $\begin{array}{c}643.5 \\
257.03\end{array}$ & $\begin{array}{l}1838.62 \\
6743.34\end{array}$ & $\begin{array}{l}0.0454 \\
0.1528\end{array}$ & $\begin{aligned} 1-\mathrm{A}^{\prime} & \rightarrow 1-\mathrm{A}^{\prime \prime} \\
1-\mathrm{A}^{\prime} & \rightarrow 1-\mathrm{A}^{\prime}\end{aligned}$ & $\begin{array}{l}371.74 \\
245.92 \\
207.81\end{array}$ & $\begin{array}{l}2862.63 \\
3892.09 \\
8252.17\end{array}$ & $\begin{array}{c}0.0707 \\
0.0951 \\
0.20411\end{array}$ & $\begin{array}{l}1-\mathrm{A}^{\prime} \rightarrow 1-\mathrm{A}^{\prime \prime} \\
1-\mathrm{A}^{\prime} \rightarrow 1-\mathrm{A}^{\prime} \\
1-\mathrm{A}^{\prime} \rightarrow 1-\mathrm{A}^{\prime}\end{array}$ \\
\hline
\end{tabular}

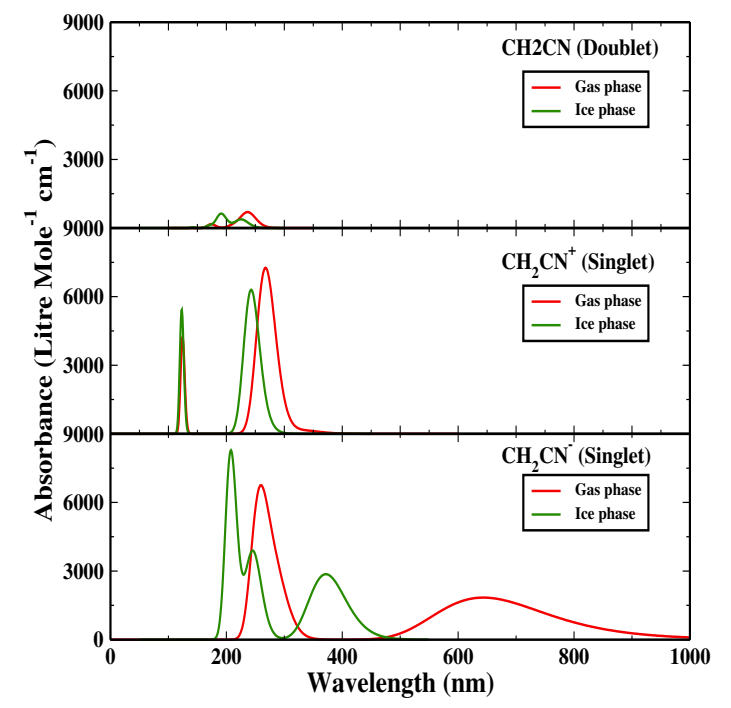

Fig. 2. Electronic absorption spectra of $\mathrm{CH}_{2} \mathrm{CN}$ (doublet), $\mathrm{CH}_{2} \mathrm{CN}^{+}$ (singlet), and $\mathrm{CH}_{2} \mathrm{CN}^{-}$(singlet) in gas phase and in ice phase.

above the lowest energy (doublet) state of $\mathrm{CH}_{2} \mathrm{CN}$ radical, the electron will be removed from the anion before it excites into these high spin states. Those states therefore cannot exist, and this is why we did not consider the higher spin states of the different forms of $\mathrm{CH}_{2} \mathrm{CN}$. In Fig. 2, we show the electronic absorption spectra of $\mathrm{CH}_{2} \mathrm{CN}, \mathrm{CH}_{2} \mathrm{CN}^{+}$, and $\mathrm{CH}_{2} \mathrm{CN}^{-}$for their stablest spin configuration. According to the discussion in Sect. 3.1, doublet $\mathrm{CH}_{2} \mathrm{CN}$, singlet $\mathrm{CH}_{2} \mathrm{CN}^{+}$, and singlet $\mathrm{CH}_{2} \mathrm{CN}^{-}$are the most stable spin states of these species. Intense peaks in Fig. 2 are assigned according to various electronic transitions shown in Table 3. It is clear that peak positions in the ice phase are shifted depending on the composition of the interstellar grain mantle. Different electronic absorption spectral parameters for $\mathrm{CH}_{2} \mathrm{CN}$, $\mathrm{CH}_{2} \mathrm{CN}^{+}$, and $\mathrm{CH}_{2} \mathrm{CN}^{-}$in both the gas and ice phases are given in Table 3.

\section{Conclusions}

There are some indications in the literature that $\mathrm{CH}_{2} \mathrm{CN}^{-}$might be the carrier of one of the many poorly characterized diffuse interstellar bands. In this paper, we investigated different ways to manifest cyanomethyl radicals in the ISM. The highlights are follow.
- We performed quantum chemical calculations to find out energetically the most stable spin configuration for various forms of $\mathrm{CH}_{2} \mathrm{CN}$.

- By introducing a large deuterated network into our chemical model, we explored the existence of different isotopologues of $\mathrm{CH}_{2} \mathrm{CN}, \mathrm{CH}_{2} \mathrm{CN}^{+}$, and $\mathrm{CH}_{2} \mathrm{CN}^{-}$(provided in the Appendix). Our chemical modeling shows that different isotopomers of various forms of $\mathrm{CH}_{2} \mathrm{CN}$ could efficiently be formed in the ISM. Column densities of various isotopomers of cyanomethyl anions are reasonably higher and could be observed with the present instrumental facility, such as, ALMA and JVLA.

- We explored the vibrational (harmonic), rotational, and electronic spectral properties of different forms of $\mathrm{CH}_{2} \mathrm{CN}$ in different astrophysical environments. Our result could be used as a guideline for observing various forms of $\mathrm{CH}_{2} \mathrm{CN}$ around ISM. In the Appendix, we have presented the rotational transitions of $\mathrm{CH}_{2} \mathrm{CN}^{-}, \mathrm{CHDCN}^{-}$, and $\mathrm{CD}_{2} \mathrm{CN}^{-}$, which could be useful for observational identifications.

Acknowledgements. L.M. is grateful to DST for partial financial support through a project (Grant No. SR/S2/HEP-40/2008) and AD wants to thank the ISRO respond project (Grant No. ISRO/RES/2/372/11-12). The authors would like to thank the anonymous referee and Prof. Malcolm Walmsley. Their valuable suggestions have helped to improve this paper significantly.

\section{Appendix A}

\section{A.1. Chemical modeling}

To study various forms of the cyanomethyl radical in the ISM, we developed a chemical model that includes the gas phase and the grain surface chemical network. Our gas phase chemical network consists of the network of Woodall et al. (2007) and the deuterated network used in Das et al. (2013b). Moreover, we include certain new reactions for the formation and destruction of various forms of cyanomethyl radical and its related species. Our surface network was mainly adopted from Das et al. (2013b) and references therein. Our present gas phase chemical network consists of 6296 reactions, and the present surface chemical network consists of 285 reactions. Except for molecular hydrogen (according to Leitch \& Williams 1985, sticking coefficient of $\mathrm{H}_{2} \sim 0$ ) and helium (Roberts \& Millar 2000 assume that helium would not stick to the grain), depletion of all the gas phase neutral species onto the grain surface are considered with a sticking probability one.

In Table A.1, we have presented only those reactions that are responsible for the formation and destruction of various deuterated isotopomers of cyanomethyl radical and its related species. 
Table A.1. Added reaction network for cyanomethyl radical and its related species.

\begin{tabular}{|c|c|c|c|}
\hline $\begin{array}{l}\text { Reaction } \\
\text { number }\end{array}$ & $\begin{array}{c}\text { Reaction } \\
\text { type }\end{array}$ & Reaction pathways for different isotopomers of Cyanomethyl radical & $\begin{array}{l}\text { Rate coefficient at } \\
T=10 \mathrm{~K} A_{V}=10\end{array}$ \\
\hline R1 & IN & $\mathrm{H}_{3}^{+}+\mathrm{CD}_{2} \mathrm{CN}\left(4.382,3.499^{\mathrm{a}}\right) \rightarrow \mathrm{CH}_{2} \mathrm{DCN}^{+}+\mathrm{HD}$ & $4.60 \times 10^{-08} \mathrm{~cm}^{3} \mathrm{~s}^{-1}$ \\
\hline $\mathrm{R} 2$ & IN & $\mathrm{He}^{+}+\mathrm{CD}_{2} \mathrm{CN}\left(4.382,3.499^{\mathrm{a}}\right) \rightarrow \mathrm{CN}+\mathrm{CD}_{2}^{+}+\mathrm{He}$ & $5.58 \times 10^{-08} \mathrm{~cm}^{3} \mathrm{~s}^{-1}$ \\
\hline R3 & IN & $\mathrm{CHD}_{2} \mathrm{CN}^{+}+\mathrm{CO}\left(1.951,0.101^{\mathrm{a}}\right) \rightarrow \mathrm{CD}_{2} \mathrm{CN}+\mathrm{HCO}^{+}$ & $1.04 \times 10^{-09} \mathrm{~cm}^{3} \mathrm{~s}^{-1}$ \\
\hline $\mathrm{R} 4$ & IN & $\mathrm{H}^{+}+\mathrm{CHD}_{2} \mathrm{CN}\left(4.315,3.932^{\mathrm{a}}\right) \rightarrow \mathrm{CD}_{2} \mathrm{CN}^{+}+\mathrm{H}_{2}$ & $8.72 \times 10^{-08} \mathrm{~cm}^{3} \mathrm{~s}^{-1}$ \\
\hline R5 & IN & $\mathrm{CD}_{2}^{+}+\mathrm{HCN}\left(2.497,3.007^{\mathrm{a}}\right) \rightarrow \mathrm{CD}_{2} \mathrm{CN}^{+}+\mathrm{H}$ & $2.08 \times 10^{-08} \mathrm{~cm}^{3} \mathrm{~s}^{-1}$ \\
\hline R6 & IN & $\mathrm{C}_{2} \mathrm{HD}^{+}+\mathrm{ND}\left(1.447,1.522^{\mathrm{a}}\right) \rightarrow \mathrm{CD}_{2} \mathrm{CN}^{+}+\mathrm{H}$ & $1.07 \times 10^{-08} \mathrm{~cm}^{3} \mathrm{~s}^{-1}$ \\
\hline R7 & IN & $\mathrm{CHD}_{2}^{+}+\mathrm{CN}\left(2.884,1.390^{\mathrm{a}}\right) \rightarrow \mathrm{CD}_{2} \mathrm{CN}^{+}+\mathrm{H}$ & $9.94 \times 10^{-09} \mathrm{~cm}^{3} \mathrm{~s}^{-1}$ \\
\hline R8 & IN & $\mathrm{C}_{2} \mathrm{D}^{+}+\mathrm{NHD}\left(1.782,1.768^{\mathrm{a}}\right) \rightarrow \mathrm{CD}_{2} \mathrm{CN}^{+}+\mathrm{H}$ & $1.22 \times 10^{-08} \mathrm{~cm}^{3} \mathrm{~s}^{-1}$ \\
\hline R9 & IN & $\mathrm{C}_{2} \mathrm{D}^{+}+\mathrm{NH}_{2} \mathrm{D}\left(2.087,1.519^{\mathrm{a}}\right) \rightarrow \mathrm{CD}_{2} \mathrm{CN}^{+}+\mathrm{H}_{2}$ & $1.05 \times 10^{-08} \mathrm{~cm}^{3} \mathrm{~s}^{-1}$ \\
\hline $\mathrm{R} 10$ & IN & $\mathrm{H}^{+}+\mathrm{CH}_{2}$ DCN $\left(4.315,3.932^{\mathrm{a}}\right) \rightarrow \mathrm{CHDCN}^{+}+\mathrm{H}_{2}$ & $8.72 \times 10^{-08} \mathrm{~cm}^{3} \mathrm{~s}^{-1}$ \\
\hline $\mathrm{R} 11$ & IN & $\mathrm{H}^{+}+\mathrm{CH}_{2} \mathrm{DCN}\left(4.315,3.932^{\mathrm{a}}\right) \rightarrow \mathrm{CH}_{2} \mathrm{D}^{+}+\mathrm{HCN}$ & $8.72 \times 10^{-08} \mathrm{~cm}^{3} \mathrm{~s}^{-1}$ \\
\hline $\mathrm{R} 12$ & IN & $\mathrm{H}^{3}++\mathrm{CH}_{2} \mathrm{DCN}\left(4.315,3.932^{\mathrm{a}}\right) \rightarrow \mathrm{CH}_{2} \mathrm{DCNH}^{+}+\mathrm{H}_{2}$ & $5.15 \times 10^{-08} \mathrm{~cm}^{3} \mathrm{~s}^{-1}$ \\
\hline $\mathrm{R} 13$ & IN & $\mathrm{He}^{+}+\mathrm{CH}_{2} \mathrm{DCN}\left(4.315,3.932^{\mathrm{a}}\right) \rightarrow \mathrm{CN}+\mathrm{CH}_{2} \mathrm{D}^{+}+\mathrm{He}$ & $6.24 \times 10^{-08} \mathrm{~cm}^{3} \mathrm{~s}^{-1}$ \\
\hline $\mathrm{R} 14$ & IN & $\mathrm{H}_{3} \mathrm{O}^{+}+\mathrm{CH}_{2} \mathrm{DCN}\left(4.315,3.932^{\mathrm{a}}\right) \rightarrow \mathrm{CH}_{2} \mathrm{DCNH}^{+}+\mathrm{H}_{2} \mathrm{O}$ & $2.38 \times 10^{-08} \mathrm{~cm}^{3} \mathrm{~s}^{-1}$ \\
\hline $\mathrm{R} 15$ & IN & $\mathrm{C}_{2} \mathrm{H}_{2}^{+}+\mathrm{CH}_{2} \mathrm{DCN}\left(4.315,3.932^{\mathrm{a}}\right) \rightarrow \mathrm{CH}_{2} \mathrm{DCNH}^{+}+\mathrm{C}_{2} \mathrm{H}$ & $2.15 \times 10^{-08} \mathrm{~cm}^{3} \mathrm{~s}^{-1}$ \\
\hline R16 & IN & $\mathrm{HCNH}^{+}+\mathrm{CH}_{2} \mathrm{DCN}\left(4.315,3.932^{\mathrm{a}}\right) \rightarrow \mathrm{CH}_{2} \mathrm{DCNH}^{+}+\mathrm{HCN}$ & $2.10 \times 10^{-08} \mathrm{~cm}^{3} \mathrm{~s}^{-1}$ \\
\hline $\mathrm{R} 17$ & IN & $\mathrm{HCNH}^{+}+\mathrm{CH}_{2} \mathrm{DCN}\left(4.315,3.932^{\mathrm{a}}\right) \rightarrow \mathrm{CH}_{2} \mathrm{DCNH}^{+}+\mathrm{HNC}$ & $2.10 \times 10^{-08} \mathrm{~cm}^{3} \mathrm{~s}^{-1}$ \\
\hline $\mathrm{R} 18$ & IN & $\mathrm{HCO}^{+}+\mathrm{CH}_{2} \mathrm{DCN}\left(4.315,3.932^{\mathrm{a}}\right) \rightarrow \mathrm{CH}_{2} \mathrm{DCNH}^{+}+\mathrm{CO}$ & $2.08 \times 10^{-08} \mathrm{~cm}^{3} \mathrm{~s}^{-1}$ \\
\hline R19 & IN & $\mathrm{HN}_{2}^{+}+\mathrm{CH}_{2} \mathrm{DCN}\left(4.315,3.932^{\mathrm{a}}\right) \rightarrow \mathrm{CH}_{2} \mathrm{DCNH}^{+}+\mathrm{N}_{2}$ & $2.08 \times 10^{-08} \mathrm{~cm}^{3} \mathrm{~s}^{-1}$ \\
\hline $\mathrm{R} 20$ & IN & $\mathrm{C}_{2} \mathrm{H}_{5}^{+}+\mathrm{CH}_{2} \mathrm{DCN}\left(4.315,3.932^{\mathrm{a}}\right) \rightarrow \mathrm{CH}_{2} \mathrm{DCNH}^{+}+\mathrm{C}_{2} \mathrm{H}_{4}$ & $2.08 \times 10^{-08} \mathrm{~cm}^{3} \mathrm{~s}^{-1}$ \\
\hline $\mathrm{R} 21$ & IN & $\mathrm{HCO}_{2}^{+}+\mathrm{CH}_{2} \mathrm{DCN}\left(4.315,3.932^{\mathrm{a}}\right) \rightarrow \mathrm{CO}_{2}+\mathrm{CH}_{2} \mathrm{DCNH}+$ & $1.85 \times 10^{-08} \mathrm{~cm}^{3} \mathrm{~s}^{-1}$ \\
\hline $\mathrm{R} 22$ & IN & $\mathrm{HCOOH}_{2}^{+}+\mathrm{CH}_{2} \mathrm{DCN}\left(4.315,3.932^{\mathrm{a}}\right) \rightarrow \mathrm{CH}_{2} \mathrm{DCNH}^{+}+\mathrm{HCOOH}$ & $1.83 \times 10^{-08} \mathrm{~cm}^{3} \mathrm{~s}^{-1}$ \\
\hline $\mathrm{R} 23$ & IN & $\mathrm{HC}_{3} \mathrm{NH}^{+}+\mathrm{CH}_{2} \mathrm{DCN}\left(4.315,3.932^{\mathrm{a}}\right) \rightarrow \mathrm{CH}_{2} \mathrm{DCNH}^{+}+\mathrm{HC}_{3} \mathrm{~N}$ & $1.79 \times 10^{-08} \mathrm{~cm}^{3} \mathrm{~s}^{-1}$ \\
\hline $\mathrm{R} 24$ & IN & $\mathrm{H}_{3}^{+}+\mathrm{CHDCN}\left(4.382,3.499^{\mathrm{a}}\right) \rightarrow \mathrm{CH}_{2} \mathrm{DCN}^{+}+\mathrm{H}_{2}$ & $4.61 \times 10^{-08} \mathrm{~cm}^{3} \mathrm{~s}^{-1}$ \\
\hline $\mathrm{R} 25$ & IN & $\mathrm{C}_{2} \mathrm{HD}^{+}+\mathrm{NH}_{2}\left(1.782,1.768^{\mathrm{a}}\right) \rightarrow \mathrm{CH}_{2} \mathrm{DCN}^{+}+\mathrm{H}$ & $1.24 \times 10^{-08} \mathrm{~cm}^{3} \mathrm{~s}^{-1}$ \\
\hline R26 & IN & $\mathrm{CH}_{2} \mathrm{DCN}^{+}+\mathrm{CO}\left(1.951,0.101^{\mathrm{a}}\right) \rightarrow \mathrm{CHDCN}+\mathrm{HCO}^{+}$ & $1.04 \times 10^{-09} \mathrm{~cm}^{3} \mathrm{~s}^{-1}$ \\
\hline $\mathrm{R} 27$ & IN & $\mathrm{CH}_{2} \mathrm{DCN}^{+}+\mathrm{H}_{2}\left(0.773,0^{\mathrm{a}}\right) \rightarrow \mathrm{CH}_{2} \mathrm{DCNH}^{+}+\mathrm{H}$ & $1.48 \times 10^{-09} \mathrm{~cm}^{3} \mathrm{~s}^{-1}$ \\
\hline $\mathrm{R} 28$ & IN & $\mathrm{C}_{2} \mathrm{H}_{7}^{+}+\mathrm{DCN}\left(2.497,3.007^{\mathrm{a}}\right) \rightarrow \mathrm{CH}_{2} \mathrm{DCNH}^{+}+\mathrm{CH}_{4}$ & $1.71 \times 10^{-08} \mathrm{~cm}^{3} \mathrm{~s}^{-1}$ \\
\hline $\mathrm{R} 29$ & IN & $\mathrm{CH}_{3} \mathrm{OH}_{2}^{+}+\mathrm{DCN}\left(2.497,3.007^{\mathrm{a}}\right) \rightarrow \mathrm{CH}_{2} \mathrm{DCNH}^{+}+\mathrm{H}_{2} \mathrm{O}$ & $1.69 \times 10^{-08} \mathrm{~cm}^{3} \mathrm{~s}^{-1}$ \\
\hline $\mathrm{R} 30$ & IN & $\mathrm{HCOOH}_{2}^{+}+\mathrm{CH}_{2} \mathrm{DCN}\left(4.315,3.932^{\mathrm{a}}\right) \rightarrow \mathrm{CH}_{2} \mathrm{DCNH}^{+}+\mathrm{HCOOH}$ & $1.83 \times 10^{-08} \mathrm{~cm}^{3} \mathrm{~s}^{-1}$ \\
\hline $\mathrm{R} 31$ & IN & $\mathrm{HC}_{3} \mathrm{NH}^{+}+\mathrm{CH}_{2} \mathrm{DCN}\left(4.315,3.932^{\mathrm{a}}\right) \rightarrow \mathrm{CH}_{2} \mathrm{DCNH}^{+}+\mathrm{HC}_{3} \mathrm{~N}$ & $1.78 \times 10^{-08} \mathrm{~cm}^{3} \mathrm{~s}^{-1}$ \\
\hline $\mathrm{R} 32$ & IN & $\mathrm{H}^{+}+\mathrm{CHD}_{2} \mathrm{CN}\left(4.315,3.932^{\mathrm{a}}\right) \rightarrow \mathrm{CHD}_{2}^{+}+\mathrm{HCN}$ & $8.72 \times 10^{-08} \mathrm{~cm}^{3} \mathrm{~s}^{-1}$ \\
\hline $\mathrm{R} 33$ & IN & $\mathrm{H}^{3}++\mathrm{CHD}_{2} \mathrm{CN}\left(4.315,3.932^{\mathrm{a}}\right) \rightarrow \mathrm{CHD}_{2} \mathrm{CNH}^{+}+\mathrm{H}_{2}$ & $5.14 \times 10^{-08} \mathrm{~cm}^{3} \mathrm{~s}^{-1}$ \\
\hline $\mathrm{R} 34$ & IN & $\mathrm{He}^{+}+\mathrm{CHD}_{2} \mathrm{CN}\left(4.315,3.932^{\mathrm{a}}\right) \rightarrow \mathrm{CN}+\mathrm{CHD}_{2}^{+}+\mathrm{He}$ & $6.23 \times 10^{-08} \mathrm{~cm}^{3} \mathrm{~s}^{-1}$ \\
\hline $\mathrm{R} 35$ & IN & $\mathrm{H}_{3} \mathrm{O}^{+}+\mathrm{CHD}_{2} \mathrm{CN}\left(4.315,3.932^{\mathrm{a}}\right) \rightarrow \mathrm{CHD}_{2} \mathrm{CNH}^{+}+\mathrm{H}_{2} \mathrm{O}$ & $2.37 \times 10^{-08} \mathrm{~cm}^{3} \mathrm{~s}^{-1}$ \\
\hline $\mathrm{R} 36$ & IN & $\mathrm{C}_{2} \mathrm{H}_{2}^{+}+\mathrm{CHD}_{2} \mathrm{CN}\left(4.315,3.932^{\mathrm{a}}\right) \rightarrow \mathrm{CHD}_{2} \mathrm{CNH}^{+}+\mathrm{C}_{2} \mathrm{H}$ & $2.14 \times 10^{-08} \mathrm{~cm}^{3} \mathrm{~s}^{-1}$ \\
\hline $\mathrm{R} 37$ & IN & $\mathrm{HCNH}^{+}+\mathrm{CHD}_{2} \mathrm{CN}\left(4.315,3.932^{\mathrm{a}}\right) \rightarrow \mathrm{CHD}_{2} \mathrm{CNH}^{+}+\mathrm{HCN}$ & $2.09 \times 10^{-08} \mathrm{~cm}^{3} \mathrm{~s}^{-1}$ \\
\hline $\mathrm{R} 38$ & IN & $\mathrm{HCNH}^{+}+\mathrm{CHD}_{2} \mathrm{CN}\left(4.315,3.932^{\mathrm{a}}\right) \rightarrow \mathrm{CHD}_{2} \mathrm{CNH}^{+}+\mathrm{HNC}$ & $2.09 \times 10^{-08} \mathrm{~cm}^{3} \mathrm{~s}^{-1}$ \\
\hline R39 & IN & $\mathrm{HCO}^{+}+\mathrm{CHD} 2 \mathrm{CN}\left(4.315,3.932^{\mathrm{a}}\right) \rightarrow \mathrm{CHD}_{2} \mathrm{CNH}^{+}+\mathrm{CO}$ & $2.07 \times 10^{-08} \mathrm{~cm}^{3} \mathrm{~s}^{-1}$ \\
\hline $\mathrm{R} 40$ & IN & $\mathrm{HN}_{2}^{+}+\mathrm{CHD}_{2} \mathrm{CN}\left(4.315,3.932^{\mathrm{a}}\right) \rightarrow \mathrm{CHD}_{2} \mathrm{CNH}^{+}+\mathrm{N}_{2}$ & $2.07 \times 10^{-08} \mathrm{~cm}^{3} \mathrm{~s}^{-1}$ \\
\hline $\mathrm{R} 41$ & IN & $\mathrm{C}_{2} \mathrm{H}_{5}^{+}+\mathrm{CHD}_{2} \mathrm{CN}\left(4.315,3.932^{\mathrm{a}}\right) \rightarrow \mathrm{CHD}_{2} \mathrm{CNH}^{+}+\mathrm{C}_{2} \mathrm{H}_{4}$ & $2.07 \times 10^{-08} \mathrm{~cm}^{3} \mathrm{~s}^{-1}$ \\
\hline $\mathrm{R} 42$ & IN & $\mathrm{HCO}_{2}^{+}+\mathrm{CHD}_{2} \mathrm{CN}\left(4.315,3.932^{\mathrm{a}}\right) \rightarrow \mathrm{CO}_{2}+\mathrm{CHD}_{2} \mathrm{CNH}^{+}$ & $1.83 \times 10^{-08} \mathrm{~cm}^{3} \mathrm{~s}^{-1}$ \\
\hline $\mathrm{R} 43$ & IN & $\mathrm{HCOOH}_{2}++\mathrm{CHD}_{2} \mathrm{CN}\left(4.315,3.932^{\mathrm{a}}\right) \rightarrow \mathrm{CHD}_{2} \mathrm{CNH}^{+}+\mathrm{HCOOH}$ & $1.81 \times 10^{-08} \mathrm{~cm}^{3} \mathrm{~s}^{-1}$ \\
\hline $\mathrm{R} 44$ & IN & $\mathrm{HC}_{3} \mathrm{NH}^{+}+\mathrm{CHD}_{2} \mathrm{CN}\left(4.315,3.932^{\mathrm{a}}\right) \rightarrow \mathrm{CHD}_{2} \mathrm{CNH}^{+}+\mathrm{HC}_{3} \mathrm{~N}$ & $1.78 \times 10^{-08} \mathrm{~cm}^{3} \mathrm{~s}^{-1}$ \\
\hline $\mathrm{R} 45$ & IN & $\mathrm{H}_{3}^{+}+\mathrm{CD}_{2} \mathrm{CN}\left(4.382,3.499^{\mathrm{a}}\right) \rightarrow \mathrm{CHD}_{2} \mathrm{CN}^{+}+\mathrm{H}_{2}$ & $4.60 \times 10^{-08} \mathrm{~cm}^{3} \mathrm{~s}^{-1}$ \\
\hline $\mathrm{R} 46$ & IN & $\mathrm{C}_{2} \mathrm{HD}^{+}+\mathrm{NHD}\left(1.782,1.768^{\mathrm{a}}\right) \rightarrow \mathrm{CHD}_{2} \mathrm{CN}^{+}+\mathrm{H}$ & $1.21 \times 10^{-08} \mathrm{~cm}^{3} \mathrm{~s}^{-1}$ \\
\hline $\mathrm{R} 47$ & IN & $\mathrm{CHD}_{2} \mathrm{CN}^{+}+\mathrm{H} 2\left(0.773,0^{\mathrm{a}}\right) \rightarrow \mathrm{CHD}_{2} \mathrm{CNH}^{+}+\mathrm{H}$ & $1.48 \times 10^{-09} \mathrm{~cm}^{3} \mathrm{~s}^{-1}$ \\
\hline $\mathrm{R} 48$ & IN & $\mathrm{H}_{3}^{+}+\mathrm{CHD}_{2} \mathrm{CN}\left(4.315,3.932^{\mathrm{a}}\right) \rightarrow \mathrm{CHD}_{2} \mathrm{CNH}^{+}+\mathrm{H}_{2}$ & $5.14 \times 10^{-08} \mathrm{~cm}^{3} \mathrm{~s}^{-1}$ \\
\hline $\mathrm{R} 49$ & IN & $\mathrm{CH}_{3} \mathrm{OHD}^{+}+\mathrm{DCN}\left(2.497,3.007^{\mathrm{a}}\right) \rightarrow \mathrm{CHD}_{2} \mathrm{CNH}^{+}+\mathrm{H}_{2} \mathrm{O}$ & $1.68 \times 10^{-08} \mathrm{~cm}^{3} \mathrm{~s}^{-1}$ \\
\hline R50 & IN & $\mathrm{He}^{+}+\mathrm{CHDCN}\left(4.382,3.499^{\mathrm{a}}\right) \rightarrow \mathrm{CN}+\mathrm{CHD}^{+}+\mathrm{He}$ & $5.58 \times 10^{-08} \mathrm{~cm}^{3} \mathrm{~s}^{-1}$ \\
\hline $\mathrm{R} 51$ & IN & $\mathrm{CHD}^{+}+\mathrm{HCN}\left(2.497,3.007^{\mathrm{a}}\right) \rightarrow \mathrm{CHDCN}^{+}+\mathrm{H}$ & $2.12 \times 10^{-08} \mathrm{~cm}^{3} \mathrm{~s}^{-1}$ \\
\hline $\mathrm{R} 52$ & IN & $\mathrm{C}_{2} \mathrm{HD}^{+}+\mathrm{NH}\left(1.447,1.522^{\mathrm{a}}\right) \rightarrow \mathrm{CHDCN}^{+}+\mathrm{H}$ & $1.09 \times 10^{-08} \mathrm{~cm}^{3} \mathrm{~s}^{-1}$ \\
\hline R53 & IN & $\mathrm{CH}_{2} \mathrm{D}^{+}+\mathrm{CN}\left(2.884,1.390^{\mathrm{a}}\right) \rightarrow \mathrm{CHDCN}^{+}+\mathrm{H}$ & $1.01 \times 10^{-08} \mathrm{~cm}^{3} \mathrm{~s}^{-1}$ \\
\hline R54 & IN & $\mathrm{C}_{2} \mathrm{D}^{+}+\mathrm{NH}_{2}\left(1.782,1.768^{\mathrm{a}}\right) \rightarrow \mathrm{CHDCN}^{+}+\mathrm{H}$ & $1.25 \times 10^{-08} \mathrm{~cm}^{3} \mathrm{~s}^{-1}$ \\
\hline R55 & IN & $\mathrm{C}_{2} \mathrm{D}++\mathrm{NH}_{3}\left(2.087,1.519^{\mathrm{a}}\right) \rightarrow \mathrm{CHDCN}^{+}+\mathrm{H}_{2}$ & $1.06 \times 10^{-08} \mathrm{~cm}^{3} \mathrm{~s}^{-1}$ \\
\hline R56 & $\mathrm{NN}$ & & $1.00 \times 10^{-10} \mathrm{~cm}^{3} \mathrm{~s}^{-1}$ \\
\hline R57 & NN & $\mathrm{C}+\mathrm{CHDCN} \rightarrow \mathrm{HC}_{3} \mathrm{~N}+\mathrm{D}$ & $1.00 \times 10^{-10} \mathrm{~cm}^{3} \mathrm{~s}^{-1}$ \\
\hline R58 & NN & $\mathrm{N}+\mathrm{C}_{2} \mathrm{H}_{2} \mathrm{D} \rightarrow \mathrm{CHDCN}+\mathrm{H}$ & $6.20 \times 10^{-11} \mathrm{~cm}^{3} \mathrm{~s}^{-1}$ \\
\hline R59 & $\mathrm{CE}$ & $\mathrm{H}^{+}+\mathrm{CD}_{2} \mathrm{CN} \rightarrow \mathrm{CD}_{2} \mathrm{CN}^{+}+\mathrm{H}$ & $6.30 \times 10^{-09} \mathrm{~cm}^{3} \mathrm{~s}^{-1}$ \\
\hline R60 & $\mathrm{CE}$ & $\mathrm{C}^{+}+\mathrm{CD}_{2} \mathrm{CN} \rightarrow \mathrm{CD}_{2} \mathrm{CN}^{+}+\mathrm{C}$ & $2.00 \times 10^{-09} \mathrm{~cm}^{3} \mathrm{~s}^{-1}$ \\
\hline
\end{tabular}

Notes. ${ }^{(a)}$ Polarizability of neutral reactants in units of $\AA^{3}$ and dipole moment in Debye (Woon \& Herbst 2009). 
Table A.1. continued.

\begin{tabular}{|c|c|c|c|}
\hline $\begin{array}{l}\text { Reaction } \\
\text { number }\end{array}$ & $\begin{array}{c}\text { Reaction } \\
\text { type }\end{array}$ & Reaction pathways for different isotopomers of Cyanomethyl radical & $\begin{array}{l}\text { Rate coefficient at } \\
T=10 \mathrm{~K} A_{V}=10\end{array}$ \\
\hline R61 & $\mathrm{CE}$ & $\mathrm{H}^{+}+\mathrm{CH}_{2} \mathrm{DCN} \rightarrow \mathrm{CH}_{2} \mathrm{DCN}^{+}+\mathrm{H}$ & $8.40 \times 10^{-09} \mathrm{~cm}^{3} \mathrm{~s}^{-1}$ \\
\hline R62 & $\mathrm{CE}$ & $\mathrm{O}^{+}+\mathrm{CH}_{2} \mathrm{DCN} \rightarrow \mathrm{CH}_{2} \mathrm{DCN}^{+}+\mathrm{O}$ & $2.94 \times 10^{-09} \mathrm{~cm}^{3} \mathrm{~s}^{-1}$ \\
\hline R63 & $\mathrm{CE}$ & $\mathrm{H}^{+}+\mathrm{CHD}_{2} \mathrm{CN} \rightarrow \mathrm{CHD}_{2} \mathrm{CN}^{+}+\mathrm{H}$ & $8.40 \times 10^{-09} \mathrm{~cm}^{3} \mathrm{~s}^{-1}$ \\
\hline $\mathrm{R} 64$ & $\mathrm{CE}$ & $\mathrm{O}^{+}+\mathrm{CHD}_{2} \mathrm{CN} \rightarrow \mathrm{CHD}_{2} \mathrm{CN}^{+}+\mathrm{O}$ & $2.94 \times 10^{-09} \mathrm{~cm}^{3} \mathrm{~s}^{-1}$ \\
\hline $\mathrm{R} 65$ & $\mathrm{CE}$ & $\mathrm{H}^{+}+\mathrm{CHDCN} \rightarrow \mathrm{CHDCN}^{+}+\mathrm{H}$ & $6.30 \times 10^{-09} \mathrm{~cm}^{3} \mathrm{~s}^{-1}$ \\
\hline R66 & $\mathrm{CE}$ & $\mathrm{C}^{+}+\mathrm{CHDCN} \rightarrow \mathrm{CHDCN}^{+}+\mathrm{C}$ & $2.00 \times 10^{-09} \mathrm{~cm}^{3} \mathrm{~s}^{-1}$ \\
\hline R67 & DR & $\mathrm{CHD}_{2} \mathrm{CN}^{+}+\mathrm{e}^{-} \rightarrow \mathrm{CD}_{2} \mathrm{CN}+\mathrm{H}$ & $8.22 \times 10^{-07} \mathrm{~cm}^{3} \mathrm{~s}^{-1}$ \\
\hline R68 & DR & $\mathrm{CHD}_{2} \mathrm{CNH}^{+}+\mathrm{e}^{-} \rightarrow \mathrm{CD}_{2} \mathrm{CN}+\mathrm{H}_{2}$ & $8.22 \times 10^{-07} \mathrm{~cm}^{3} \mathrm{~s}^{-1}$ \\
\hline R69 & DR & $\mathrm{CD}_{2} \mathrm{CN}^{+}+\mathrm{e}^{-} \rightarrow \mathrm{CN}+\mathrm{CD}_{2}$ & $8.22 \times 10^{-07} \mathrm{~cm}^{3} \mathrm{~s}^{-1}$ \\
\hline R70 & DR & $\mathrm{CD}_{2} \mathrm{CN}^{+}+\mathrm{e}^{-} \rightarrow \mathrm{DCN}+\mathrm{CD}$ & $8.22 \times 10^{-07} \mathrm{~cm}^{3} \mathrm{~s}^{-1}$ \\
\hline R71 & DR & $\mathrm{CH}_{2} \mathrm{DCNH}^{+}+\mathrm{e}^{-} \rightarrow \mathrm{CH}_{2} \mathrm{DCN}+\mathrm{H}$ & $8.22 \times 10^{-07} \mathrm{~cm}^{3} \mathrm{~s}^{-1}$ \\
\hline R72 & DR & $\mathrm{CH}_{2} \mathrm{DCN}^{+}+\mathrm{e}^{-} \rightarrow \mathrm{DCN}+\mathrm{CH}_{2}$ & $8.22 \times 10^{-07} \mathrm{~cm}^{3} \mathrm{~s}^{-1}$ \\
\hline R73 & DR & $\mathrm{CH}_{2} \mathrm{DCN}^{+}+\mathrm{e}^{-} \rightarrow \mathrm{CHDCN}+\mathrm{H}$ & $8.22 \times 10^{-07} \mathrm{~cm}^{3} \mathrm{~s}^{-1}$ \\
\hline R74 & DR & $\mathrm{CHD}_{2} \mathrm{CNH}^{+}+\mathrm{e}^{-} \rightarrow \mathrm{CHD}_{2} \mathrm{CN}+\mathrm{H}$ & $8.22 \times 10^{-07} \mathrm{~cm}^{3} \mathrm{~s}^{-1}$ \\
\hline R75 & DR & $\mathrm{CHD}_{2} \mathrm{CN}^{+}+\mathrm{e}^{-} \rightarrow \mathrm{DCN}+\mathrm{CHD}$ & $8.22 \times 10^{-07} \mathrm{~cm}^{3} \mathrm{~s}^{-1}$ \\
\hline R76 & DR & $\mathrm{CH}_{2} \mathrm{DCNH}^{+}+\mathrm{e}^{-} \rightarrow \mathrm{CHDCN}+\mathrm{H}_{2}$ & $8.22 \times 10^{-07} \mathrm{~cm}^{3} \mathrm{~s}^{-1}$ \\
\hline R77 & DR & $\mathrm{CHDCN}^{+}+\mathrm{e}^{-} \rightarrow \mathrm{CN}+\mathrm{CHD}$ & $8.22 \times 10^{-07} \mathrm{~cm}^{3} \mathrm{~s}^{-1}$ \\
\hline R78 & DR & $\mathrm{CHDCN}^{+}+\mathrm{e}^{-} \rightarrow \mathrm{DCN}+\mathrm{CH}$ & $8.22 \times 10^{-07} \mathrm{~cm}^{3} \mathrm{~s}^{-1}$ \\
\hline R79 & $\mathrm{PH}$ & $\mathrm{CH}_{2} \mathrm{DCN}+\mathrm{PHOTON} \rightarrow \mathrm{CH}_{2} \mathrm{DCN}^{+}+\mathrm{e}^{-}$ & $2.13 \times 10^{-23} \mathrm{~s}^{-1}$ \\
\hline R80 & $\mathrm{PH}$ & $\mathrm{CH}_{2} \mathrm{DCN}+\mathrm{PHOTON} \rightarrow \mathrm{CN}+\mathrm{CH}_{2} \mathrm{D}$ & $7.01 \times 10^{-18} s^{-1}$ \\
\hline $\mathrm{R} 81$ & $\mathrm{PH}$ & $\mathrm{CHD}_{2} \mathrm{CN}+\mathrm{PHOTON} \rightarrow \mathrm{CHD}_{2} \mathrm{CN}^{+}+\mathrm{e}^{-}$ & $2.13 \times 10^{-23} \mathrm{~s}^{-1}$ \\
\hline $\mathrm{R} 82$ & $\mathrm{PH}$ & $\mathrm{CHD}_{2} \mathrm{CN}+\mathrm{PHOTON} \rightarrow \mathrm{CN}+\mathrm{CHD}_{2}$ & $7.01 \times 10^{-18} s^{-1}$ \\
\hline R83 & CRP & $\mathrm{CH}_{2} \mathrm{DCN}+\mathrm{CRPHOT} \rightarrow \mathrm{CH}_{2} \mathrm{DCN}^{+}+\mathrm{e}^{-}$ & $3.65 \times 10^{-14} \mathrm{~s}^{-1}$ \\
\hline $\mathrm{R} 84$ & CRP & $\mathrm{CH}_{2} \mathrm{DCN}+\mathrm{CRPHOT} \rightarrow \mathrm{CN}+\mathrm{CH}_{2} \mathrm{D}$ & $7.76 \times 10^{-14} \mathrm{~s}^{-1}$ \\
\hline $\mathrm{R} 85$ & CRP & $\mathrm{CHD}_{2} \mathrm{CN}+\mathrm{CRPHOT} \rightarrow \mathrm{CHD}_{2} \mathrm{CN}^{+}+\mathrm{e}^{-}$ & $3.65 \times 14^{-17} \mathrm{~s}^{-1}$ \\
\hline R86 & CRP & $\mathrm{CHD}_{2} \mathrm{CN}+\mathrm{CRPHOT} \rightarrow \mathrm{CN}+\mathrm{CHD}_{2}$ & $7.76 \times 10^{-14} s^{-1}$ \\
\hline R87 & RA & $\mathrm{CH}_{2} \mathrm{D}+\mathrm{CN} \rightarrow \mathrm{CH}_{2} \mathrm{DCN}+$ PHOTON & $1.00 \times 10^{-16} \mathrm{~cm}^{3} \mathrm{~s}^{-1}$ \\
\hline R88 & RA & $\mathrm{CH}_{2} \mathrm{D}^{+}+\mathrm{HCN} \rightarrow \mathrm{CH}_{2} \mathrm{DCNH}++\mathrm{PHOTON}$ & $4.93 \times 10^{-08} \mathrm{~cm}^{3} \mathrm{~s}^{-1}$ \\
\hline R89 & RA & $\mathrm{CHD}_{2}+\mathrm{CN} \rightarrow \mathrm{CHD}_{2} \mathrm{CN}+$ PHOTON & $1.00 \times 10^{-16} \mathrm{~cm}^{3} \mathrm{~s}^{-1}$ \\
\hline R90 & RA & $\mathrm{CHD}_{2}^{+}+\mathrm{HCN} \rightarrow \mathrm{CHD}_{2} \mathrm{CNH}^{+}+\mathrm{PHOTON}$ & $4.93 \times 10^{-08} \mathrm{~cm}^{3} \mathrm{~s}^{-1}$ \\
\hline R91 & $\mathrm{AD}$ & $\mathrm{CH}_{2} \mathrm{D}+\mathrm{CN}^{-} \rightarrow \mathrm{CH}_{2} \mathrm{DCN}+\mathrm{e}^{-}$ & $1.00 \times 10^{-09} \mathrm{~cm}^{3} \mathrm{~s}^{-1}$ \\
\hline R92 & $\mathrm{AD}$ & $\mathrm{CHD}_{2}+\mathrm{CN}^{-} \rightarrow \mathrm{CHD}_{2} \mathrm{CN}+\mathrm{e}^{-}$ & $1.00 \times 10^{-09} \mathrm{~cm}^{3} \mathrm{~s}^{-1}$ \\
\hline R93 & REA & $\mathrm{CH}_{2} \mathrm{CN}+\mathrm{e}^{-} \rightarrow \mathrm{CH}_{2} \mathrm{CN}^{-}+$PHOTON & $6.85 \times 10^{-7} \mathrm{~cm}^{3} \mathrm{~s}^{-1}$ \\
\hline R94 & REA & $\mathrm{CD}_{2} \mathrm{CN}+\mathrm{e}^{-} \rightarrow \mathrm{CD}_{2} \mathrm{CN}^{-}+$PHOTON & $6.85 \times 10^{-7} \mathrm{~cm}^{3} \mathrm{~s}^{-1}$ \\
\hline R95 & REA & $\mathrm{CHDCN}+\mathrm{e}^{-} \rightarrow \mathrm{CHDCN}^{-}+\mathrm{PHOTON}^{-}$ & $6.85 \times 10^{-7} \mathrm{~cm}^{3} \mathrm{~s}^{-1}$ \\
\hline R96 & $\mathrm{MN}$ & $\mathrm{CH}_{2} \mathrm{CN}^{-}+\mathrm{H}_{3}^{+} \rightarrow \mathrm{CH}_{2} \mathrm{CN}+\mathrm{H}_{2}+\mathrm{H}$ & $4.11 \times 10^{-7} \mathrm{~cm}^{3} \mathrm{~s}^{-1}$ \\
\hline R97 & MN & $\mathrm{CH}_{2} \mathrm{CN}^{-}+\mathrm{C}^{+} \rightarrow \mathrm{CH}_{2} \mathrm{CN}+\mathrm{C}$ & $4.11 \times 10^{-7} \mathrm{~cm}^{3} \mathrm{~s}^{-1}$ \\
\hline R98 & MN & $\mathrm{CH}_{2} \mathrm{CN}^{-}+\mathrm{H}_{3} \mathrm{O}+\rightarrow \mathrm{CH}_{2} \mathrm{CN}+\mathrm{H}+\mathrm{H}_{2} \mathrm{O}$ & $4.11 \times 10^{-7} \mathrm{~cm}^{3} \mathrm{~s}^{-1}$ \\
\hline R99 & MN & $\mathrm{CH}_{2} \mathrm{CN}^{-}+\mathrm{HCO}^{+} \rightarrow \mathrm{CH}_{2} \mathrm{CN}+\mathrm{H}+\mathrm{CO}$ & $4.11 \times 10^{-7} \mathrm{~cm}^{3} \mathrm{~s}^{-1}$ \\
\hline $\mathrm{R} 100$ & MN & $\mathrm{CH}_{2} \mathrm{CN}^{-}+\mathrm{HN}_{2}^{+} \rightarrow \mathrm{CH}_{2} \mathrm{CN}+\mathrm{H}+\mathrm{N}_{2}$ & $4.11 \times 10^{-7} \mathrm{~cm}^{3} \mathrm{~s}^{-1}$ \\
\hline R101 & MN & $\mathrm{CH}_{2} \mathrm{CN}^{-}+\mathrm{O}^{+} \rightarrow \mathrm{CH}_{2} \mathrm{CN}+\mathrm{O}$ & $4.11 \times 10^{-7} \mathrm{~cm}^{3} \mathrm{~s}^{-1}$ \\
\hline R102 & MN & $\mathrm{CH}_{2} \mathrm{CN}^{-}+\mathrm{H}^{+} \rightarrow \mathrm{CH}_{2} \mathrm{CN}+\mathrm{H}$ & $4.11 \times 10^{-7} \mathrm{~cm}^{3} \mathrm{~s}^{-1}$ \\
\hline R103 & $\mathrm{MN}$ & $\mathrm{CHDCN}^{-}+\mathrm{H}_{3}+\rightarrow \mathrm{CHDCN}+\mathrm{H}_{2}+\mathrm{H}$ & $4.11 \times 10^{-7} \mathrm{~cm}^{3} \mathrm{~s}^{-1}$ \\
\hline R104 & MN & $\mathrm{CHDCN}^{-}+\mathrm{C}+\rightarrow \mathrm{CHDCN}+\mathrm{C}$ & $4.11 \times 10^{-7} \mathrm{~cm}^{3} \mathrm{~s}^{-1}$ \\
\hline R105 & $\mathrm{MN}$ & $\mathrm{CHDCN}^{-}+\mathrm{H}_{3} \mathrm{O}^{+} \rightarrow \mathrm{CHDCN}+\mathrm{H}+\mathrm{H}_{2} \mathrm{O}$ & $4.11 \times 10^{-7} \mathrm{~cm}^{3} \mathrm{~s}^{-1}$ \\
\hline R106 & $\mathrm{MN}$ & $\mathrm{CHDCN}^{-}+\mathrm{HCO}^{+} \rightarrow \mathrm{CHDCN}+\mathrm{H}+\mathrm{CO}$ & $4.11 \times 10^{-7} \mathrm{~cm}^{3} \mathrm{~s}^{-1}$ \\
\hline R107 & $\mathrm{MN}$ & $\mathrm{CHDCN}^{-}+\mathrm{HN}_{2}^{+} \rightarrow \mathrm{CHDCN}+\mathrm{H}+\mathrm{N}_{2}$ & $4.11 \times 10^{-7} \mathrm{~cm}^{3} \mathrm{~s}^{-1}$ \\
\hline R108 & MN & $\mathrm{CHDCN}^{-}+\mathrm{O}^{+} \rightarrow \mathrm{CHDCN}+\mathrm{O}$ & $4.11 \times 10^{-7} \mathrm{~cm}^{3} \mathrm{~s}^{-1}$ \\
\hline R109 & MN & $\mathrm{CHDCN}^{-}+\mathrm{H}^{+} \rightarrow \mathrm{CHDCN}+\mathrm{H}$ & $4.11 \times 10^{-7} \mathrm{~cm}^{3} \mathrm{~s}^{-1}$ \\
\hline R110 & $\mathrm{MN}$ & $\mathrm{CD}_{2} \mathrm{CN}^{-}+\mathrm{H}_{3}^{+} \rightarrow \mathrm{CD}_{2} \mathrm{CN}+\mathrm{H}_{2}+\mathrm{H}$ & $4.11 \times 10^{-7} \mathrm{~cm}^{3} \mathrm{~s}^{-1}$ \\
\hline R111 & MN & $\mathrm{CD}_{2} \mathrm{CN}^{-}+\mathrm{C}^{+} \rightarrow \mathrm{CD}_{2} \mathrm{CN}+\mathrm{C}$ & $4.11 \times 10^{-7} \mathrm{~cm}^{3} \mathrm{~s}^{-1}$ \\
\hline R112 & MN & $\mathrm{CD}_{2} \mathrm{CN}^{-}+\mathrm{H}_{3} \mathrm{O}^{+} \rightarrow \mathrm{CD}_{2} \mathrm{CN}+\mathrm{H}+\mathrm{H}_{2} \mathrm{O}$ & $4.11 \times 10^{-7} \mathrm{~cm}^{3} \mathrm{~s}^{-1}$ \\
\hline $\mathrm{R} 113$ & MN & $\mathrm{CD}_{2} \mathrm{CN}^{-}+\mathrm{HCO}^{+} \rightarrow \mathrm{CD}_{2} \mathrm{CN}+\mathrm{H}+\mathrm{CO}$ & $4.11 \times 10^{-7} \mathrm{~cm}^{3} \mathrm{~s}^{-1}$ \\
\hline R114 & MN & $\mathrm{CD}_{2} \mathrm{CN}^{-}+\mathrm{HN}_{2}^{+} \rightarrow \mathrm{CD}_{2} \mathrm{CN}+\mathrm{H}+\mathrm{N}_{2}$ & $4.11 \times 10^{-7} \mathrm{~cm}^{3} \mathrm{~s}^{-1}$ \\
\hline R115 & MN & $\mathrm{CD}_{2} \mathrm{CN}^{-}+\mathrm{O}^{+} \rightarrow \mathrm{CD}_{2} \mathrm{CN}+\mathrm{O}$ & $4.11 \times 10^{-7} \mathrm{~cm}^{3} \mathrm{~s}^{-1}$ \\
\hline R116 & $\mathrm{MN}$ & $\mathrm{CD}_{2} \mathrm{CN}^{-}+\mathrm{H}^{+} \rightarrow \mathrm{CD} 2 \mathrm{CN}+\mathrm{H}$ & $4.11 \times 10^{-7} \mathrm{~cm}^{3} \mathrm{~s}^{-1}$ \\
\hline
\end{tabular}

Various types of reactions are considered in the network, namely, ion(cation)-neutral (IN), neutral-neutral (NN), charge exchange $(\mathrm{CE})$, dissociative recombination (DR), photo-dissociation (PH), cosmic ray induced photo-dissociation (CRP), radiative association (RA), associative detachment (AD), radiative electron attachment (REA), and mutual neutralization $(\mathrm{MN})$. The reaction 
network given in Table A.1 is constructed mainly by assuming that reaction pathways are similar to those of hydrogenated reactions in Woodall et al. (2007). Following are the adequate discussion regarding the adopted network for the various forms of cyanomethyl radical and its related species.

\section{lon-neutral}

Ion(cation)-neutral reactions $\left(A^{+}+B \rightarrow C^{+}+D\right)$ are the dominant means for the destroying of a neutral interstellar species. All the deuterated ion neutral reactions are assumed to be similar to the corresponding hydrogenated reactions given in the network of Woodall et al. (2007). The reaction numbers from R1 to R55 of Table A.1 are of this kind. According to Herbst (2006), for a ion-molecular reaction, rate coefficient can be determined using the capture theory where the translational energy of the reactant must only surpass a lon-range centrifugal barrier for the reaction to occur. The collision rate coefficient between an ion and non-polar neutral molecule can be determined using the socalled Langevin collision rate

$k_{\mathrm{L}}=2 \pi e \sqrt{\frac{\alpha_{d}}{\mu}}$,

where e is the electronic charge, $\alpha$ the polarizibility of the neutral non-polar molecule in $\AA^{3}, \mu$ the reduced mass of the reactants. But for polar neutral species, a complex situation arises due to the attraction between a charge and rotating permanent dipole moment. Su \& Chesnavich (1982) predicted the rate coefficients for this type of reactions. According to Woon \& Herbst (2009), the Su-Chesnavich formula can be written in two different ways and both use a parameter

$x=\mu_{\mathrm{D}} / \sqrt{2 \alpha k T}$,

where $k$ is the Boltzmann constant, $\mu_{\mathrm{D}}$ the dipole moment of the polar neutral species in Debye, and $T$ is the temperature in Kelvin. Depending on the values of " $x$ ", rate coefficients could be calculated by following two equations:

$k_{\mathrm{IN}}=(0.4767 x+0.6200) k_{\mathrm{L}}$ for $x \geq 2$,

$k_{\mathrm{IN}}=\left[(x+0.5090)^{2} / 10.526+0.9754\right] k_{\mathrm{L}}$ for $x<2$.

For $x=0$, these equations reduce to the Langevin expression. Alternatively, Woon \& Herbst (2009) express the equation for $x \geq 2$ in powers of temperature $T$ as;

$k_{\mathrm{IN}}=c_{1}+c_{2} / \sqrt{T}$,

where $c_{1}=0.62 k_{\mathrm{L}}$ and $c_{2}=\left(0.4767 \mu_{\mathrm{D}} / \sqrt{2 \alpha k} k_{\mathrm{L}}\right.$.

For computing of the rate coefficients, the value of the polarizibility and the dipole moment of the neutral molecules are taken from Woon \& Herbst (2009). Here we have considered that polarizibility and dipole moment will be invariant under the isotopic substitution. Theoretical computation of the polarizibility and dipole moment depends on the derivatives of the electronic energy with respect to the external electric field. Since this electronic energy does not depend on the mass of the nuclei (since the calculations are based on the Born-Oppenheimer approximation), isotopic substitution will not affect the results. But, since isotopic substitution changes the effective reduced mass of the reactants, the rate coefficients for the deuterated reactions could be different. Computed rate coefficients for the reaction numbers from R1 to R55 are also given in Table A.1 for $T=10 \mathrm{~K}$. Polarizibility of the neutral reactants in the unit of $\AA^{3}$ and their respective dipole moments in the unit of Debye, which are used for the computation of the rate coefficients, are also given in Table A.1.

\section{Neutral-neutral}

Reaction numbers R56 to R58 of Table A.1 are the neutralneutral $(A+B \rightarrow C+D)$ type reactions. From Woodall et al. (2007), we took those neutral-neutral reactions where neutral $\mathrm{CH}_{2} \mathrm{CN}$ is involved and assumed that similar reactions would be possible for its deuterated isotopomers. For the computation of rate coefficients for the neutral-neutral reactions, one needs to calculate the electronic energy barrier. But this electronic energy barrier is independent of the atomic mass. For this reason, we have assumed that the rate coefficients is similar to those values for neutral $\mathrm{CH}_{2} \mathrm{CN}$ in Woodall et al. (2007). In Woodall et al. (2007), rate coefficients of this type of reactions were calculated by

$k_{\mathrm{NN}}=\alpha\left(\frac{T}{300}\right)^{\beta} \exp \left(\frac{-\gamma}{T}\right)$,

where, $\alpha, \beta$, and $\gamma$ are the three constants. For reaction R56 \& R57, we assumed that $\alpha=1 \times 10^{-10}, \beta=0$ and $\gamma=0$ by following the reaction $\mathrm{C}+\mathrm{CH}_{2} \mathrm{CN} \rightarrow \mathrm{HC}_{3} \mathrm{~N}+\mathrm{H}$ in Woodall et al. (2007) (Smith et al. 2004) and for the reaction R58, we have assumed $\alpha=6.2 \times 10^{-11}, \beta=0$ and $\gamma=0$ by following the reaction $\mathrm{N}+\mathrm{C}_{2} \mathrm{H}_{3} \rightarrow \mathrm{CH}_{2} \mathrm{CN}+\mathrm{H}$ in Woodall et al. (2007). Woodall et al. (2007), used these rate coefficients by following Smith et al. (2004).

\section{Charge exchange}

Charge exchange $\left(A^{+}+B \rightarrow A+B^{+}\right)$type reactions are very common in the ISM. We have considered eight reactions (R59R66) of this type. Rate constants $(\alpha, \beta \& \gamma)$ of these reactions are also assumed to be similar to their hydrogenated counterpart as mentioned in Woodall et al. (2007) and the rate coefficients are calculated by using Eq. (A.5). Woodall et al. (2007) use $\alpha=$ $6.3 \times 10^{-9}, \beta=0$ and $\gamma=0$ for $\mathrm{H}^{+}+\mathrm{CH}_{2} \mathrm{CN} \rightarrow \mathrm{CH}_{2} \mathrm{CN}^{+}+\mathrm{H}$. We have assumed that these values are also applicable for the reactions containing deuterated isotopomers of $\mathrm{CH}_{2} \mathrm{CN}$.

\section{Dissociative recombination}

Interstellar cations are mainly destroyed by the dissociative recombination $\left(A+\mathrm{e}^{-} \rightarrow C+D\right)$ processes. In our network, R67R78 are of this kind. Dissociative recombination reaction pathways for the deuterated species are developed by following the pathways available for $\mathrm{CH}_{3} \mathrm{CN}^{+}, \mathrm{CH}_{3} \mathrm{CNH}^{+}$, and $\mathrm{CH}_{2} \mathrm{CN}^{+}$from Woodall et al. (2007). Rate coefficients for the reaction numbers from R67 to R78 are computed by using Eq. (A.1). As before, we assume here that the isotopic substitution does not influence the computed rate coefficients very much. The rate constants $(\alpha, \beta, \& \gamma)$ of the deuterated reactants are assumed to be similar to the hydrogenated reactions in Woodall et al. (2007). For the reaction R67-R78, $\alpha=1.5 \times 10^{-7}, \beta=-0.5$ and $\gamma=0$ are used by following the DR channel of $\mathrm{CH}_{3} \mathrm{CN}^{+}, \mathrm{CH}_{3} \mathrm{CNH}^{+}$, and $\mathrm{CH}_{2} \mathrm{CN}^{+}$used in Woodall et al. (2007). Typical values of these kinds of rate coefficients are $\sim 10^{-7} \mathrm{~cm}^{3} \mathrm{~s}^{-1}$.

\section{Photo-dissociation}

Reaction numbers $\mathrm{R} 79$ to $\mathrm{R} 82$ of Table A.1 are the photodissociation reactions $\left(A B+h v \rightarrow A+B / A B+h v \rightarrow A B^{+}+\mathrm{e}^{-}\right)$. These reactions are taken from Woodall et al. (2007) and are applied for the deuterated reactions as well. They have considered these dissociation reactions for $\mathrm{CH}_{3} \mathrm{CN}$ and here, we assumed that these dissociation reactions are also possible for $\mathrm{CH}_{2} \mathrm{DCN}$ 
and $\mathrm{CHD}_{2} \mathrm{CN}$. For the photo-dissociation reaction of $\mathrm{CH}_{3} \mathrm{CN}$, Woodall et al. (2007) assumed that there would be two branching ratio:

$$
\begin{aligned}
& \mathrm{CH}_{3} \mathrm{CN}+\mathrm{h} v \rightarrow \mathrm{CH}_{3} \mathrm{CN}^{+}+\mathrm{e}^{-}, \\
& \mathrm{CH}_{3} \mathrm{CN}+\mathrm{h} v \rightarrow \mathrm{CH}_{3}+\mathrm{CN} .
\end{aligned}
$$

For the first reaction, $\alpha=6.2 \times 10^{-10}, \beta=0$ and $\gamma=3.1$ were assumed and for the second reaction, $\alpha=3.4 \times 10^{-9}, \beta=0$ and $\gamma=2.0$ were assumed. Here, we have adopted similar values for the deuterated reactions. Following Woodall et al. (2007), the rate coefficient for these reactions could be adopted as

$k_{\mathrm{PH}}=\alpha \exp \left(\gamma A_{V}\right) \mathrm{s}^{-1}$,

where $A_{V}$ is the visual extinction parameter. In Table A.1, we present the rate coefficients for all the reactions having $T=10 \mathrm{~K}$ and $A_{V}=10$ (cold and dense cloud condition).

\section{Cosmic ray induced photo-dissociation}

In Table A.1, the reaction numbers from $\mathrm{R} 83$ to $\mathrm{R} 86$ are for cosmic ray induced photo-dissociation $\left(A+C R P \rightarrow A^{+}+\mathrm{e}^{-} / A+\right.$ $C R P \rightarrow C+D)$. Rate coefficients for these kinds of reactions could be adopted as

$k_{\mathrm{CR}}(T)=\alpha\left(\frac{T}{300}\right)^{\beta} \frac{\gamma}{(1-\omega)}$,

where $\alpha$ is the cosmic-ray ionization rate, $\gamma$ the probability per cosmic-ray ionization that the appropriate photo reaction taking place, and $\omega$ the dust grain albedo in the far ultraviolet. Following Woodall et al. (2007), we use the cosmic ray ionization rate of $\alpha=1.3 \times 10^{-17}$ and $\omega=0.6$. These reactions (R83R86) are taken from Woodall et al. (2007) and are applied to the deuterated reactions here. Woodall et al. (2007) assume two photo-dissociation channels for $\mathrm{CH}_{3} \mathrm{CN}$. They used $\gamma=1122.5$ and 2388.0 and $\beta=0$ and 0 for these two channels. We used same values of $\beta \& \gamma$ for the dissociation channels of $\mathrm{CH}_{2} \mathrm{DCN}$, and $\mathrm{CHD}_{2} \mathrm{CN}$.

\section{Radiative association}

The reaction numbers from $\mathrm{R} 87$ to $\mathrm{R} 90$ of Table A.1 are the radiative association type reactions $(A+B \rightarrow C+h v)$. These reactions, along with the rate coefficients are taken from the hydrogenated reactions of Woodall et al. (2007) and applied here for the deuterated reactions. Rate coefficients of these reactions are calculated by using Eq. (A.5). Following the reaction $\mathrm{CH}_{3}+\mathrm{CN} \rightarrow \mathrm{CH}_{3} \mathrm{CN}+\mathrm{h} v$ in Woodall et al. (2007), we have assumed that reaction $\mathrm{R} 87$ and $\mathrm{R} 89$ would also possible with $\alpha=1 \times 10^{-16}, \beta=0$ and $\gamma=0$. Woodall et. al. (2007) considered this rate coefficients by following Prasad \& Huntress (1980). Similarly, by following the reaction $\mathrm{CH}_{3}^{+}+\mathrm{HCN} \rightarrow$ $\mathrm{CH}_{3} \mathrm{CNH}^{+}+\mathrm{h} v$ in Woodall et al. (2007) (adopted it from Herbst 1985), we have assumed that similar reaction would be possible for the deuterated species (reaction R88 and R90) having $\alpha=9.0 \times 10^{-9}, \beta=-0.5$, and $\gamma=0$.

\section{Associative detachment}

R91 and R92 of Table A.1 are the associative detachment type $\left(A+B^{-} \rightarrow C+\mathrm{e}^{-}\right)$reactions. These are taken from Woodall et al. (2007) for the formation of $\mathrm{CH}_{3} \mathrm{CN}$ and are applied here for the deuterated reactions. Rate constants are assumed to be the same
Table A.2. Initial abundances relative to the total hydrogen nuclei.

\begin{tabular}{lc}
\hline \hline Species & Abundance \\
\hline $\mathrm{H}_{2}$ & $5.00 \times 10^{-01}$ \\
$\mathrm{He}$ & $1.00 \times 10^{-01}$ \\
$\mathrm{~N}$ & $2.14 \times 10^{-05}$ \\
$\mathrm{O}$ & $1.76 \times 10^{-04}$ \\
$\mathrm{H}_{3}^{+}$ & $1.00 \times 10^{-11}$ \\
$\mathrm{C}^{+}$ & $7.30 \times 10^{-05}$ \\
$\mathrm{~S}^{+}$ & $8.00 \times 10^{-08}$ \\
$\mathrm{Si}^{+}$ & $8.00 \times 10^{-09}$ \\
$\mathrm{Fe}^{+}$ & $3.00 \times 10^{-09}$ \\
$\mathrm{Na}^{+}$ & $2.00 \times 10^{-09}$ \\
$\mathrm{Mg}^{+}$ & $7.00 \times 10^{-09}$ \\
$\mathrm{P}^{+}$ & $3.00 \times 10^{-09}$ \\
$\mathrm{Cl}^{+}$ & $4.00 \times 10^{-09}$ \\
$\mathrm{e}^{-}$ & $7.31 \times 10^{-05}$ \\
$\mathrm{HD}$ & $1.6 \times 10^{-05}$ \\
\hline
\end{tabular}

and are computed by using Eq. (A.5). $\alpha=1 \times 10^{-9}, \beta=0$ and $\gamma=0$, and were adopted in Woodall et al. (2007) for the reaction $\mathrm{CH}_{3}+\mathrm{CN}^{-} \rightarrow \mathrm{CH}_{3} \mathrm{CN}+\mathrm{e}^{-}$. Here we assumed similar values of $\alpha, \beta$, and $\gamma$ for the reactions $\mathrm{R} 91$ and $\mathrm{R} 92$.

\section{Radiative electron attachment}

The anions $\left(\mathrm{CH}_{2} \mathrm{CN}^{-}, \mathrm{CHDCN}^{-}\right.$, and $\left.\mathrm{CD}_{2} \mathrm{CN}^{-}\right)$are formed primarily via radiative electron attachment $\left(A+\mathrm{e}^{-} \rightarrow A^{-}+h v\right)$ reactions (the reaction numbers from R93 to R95 of Table A.1). Following McElroy et al. (2009), we have adopted the following formula for the computation of the rate coefficient of this type:

$$
k_{\mathrm{REA}}=1.25 \times 10^{-7}\left(\frac{T}{300}\right)^{-0.5} \mathrm{~cm}^{3} \mathrm{~s}^{-1} .
$$

\section{Mutual neutralization}

Interstellar anions could be destroyed efficiently by the cations. These types of reactions are called mutual neutralization reaction $\left(A^{-}+B^{+} \rightarrow A+B\right)$. Reaction numbers R96 to R116 of Table A.1 are of this type. According to Das et al. (2013b), $\mathrm{H}_{3}^{+}$, $\mathrm{C}^{+}, \mathrm{H}_{3} \mathrm{O}^{+}, \mathrm{HCO}^{+}, \mathrm{HN}_{2}^{+}, \mathrm{O}^{+}$, and $\mathrm{H}^{+}$are the major interstellar cations. For the mutual neutralization reactions, we have taken the reactions between these cations and different isotopomers of $\mathrm{CH}_{2} \mathrm{CN}^{-}$. Following Walsh et al. (2009), the rate coefficients of these reactions are computed by following relationship:

$k_{\mathrm{MN}}=7.5 \times 10^{-8}\left(\frac{T}{300}\right)^{-0.5} \mathrm{~cm}^{3} \mathrm{~s}^{-1}$

\section{A.2. Chemical evolution and deuterium enrichment}

Depending on the concentration of the gas phase species, all the neutral species (except $\mathrm{H}_{2}$ and $\mathrm{He}$ ) are allowed to accrete onto the grain surface. Surface species are allowed to populate the gas phase by the thermal evaporation or cosmic ray induced evaporation processes. Initial elemental abundances have been chosen to be same as in Das et al. (2013b), and these are the typical low metal abundances often adopted for TMC-1 cloud. Initial elemental abundances are given in Table A.2. Unless otherwise stated, we assume the initial abundance of HD to be $1.6 \times 10^{-5}$ with respect to total hydrogen nuclei. This implies the initial fractionation ratio $\left(\mathrm{HD} / \mathrm{H}_{2}\right) 3.2 \times 10^{-5}$. 


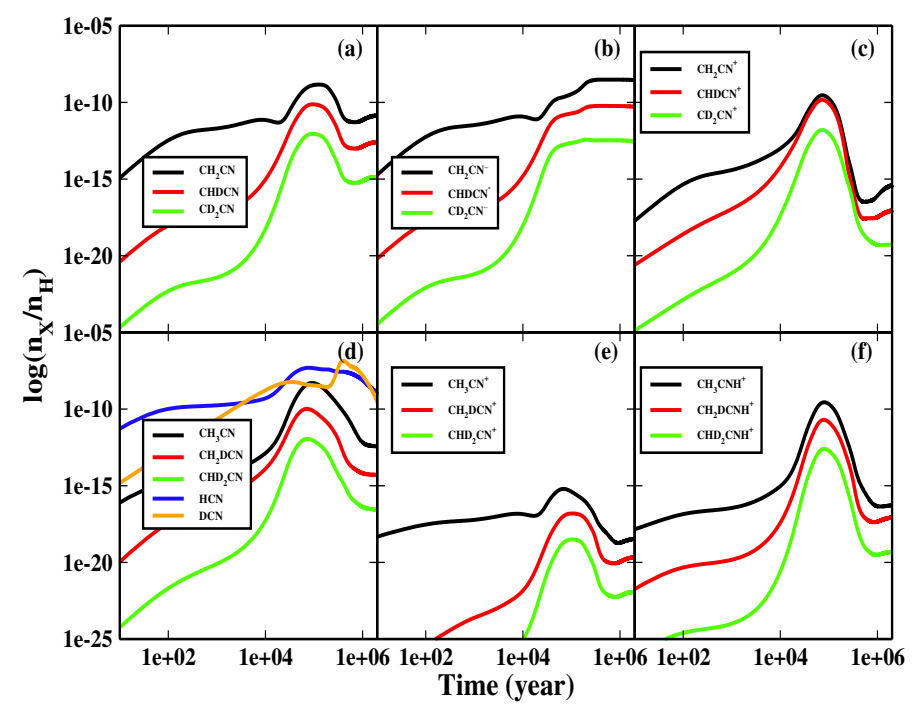

Fig. A.1. a)-f) Chemical evolution of the cyanomethyl radical and its related species.

According to Palmeirim et al. (2013) and references therein, interstellar filaments could play a fundamental role in the star formation process. Taurus molecular cloud were known to exhibit large scale filamentary structure long before Herschel (Schneider \& Elmegreen 1979; Goldsmith et al. 2008). TMC-1 has recently been mapped with Herschel (Pilbratt et al. 2010) as a part of the Gould Belt Survey (Andre et al. 2010). Results obtained from the Herschel Gould Belt survey confirm the omnipresence of parsec scale filaments in nearby molecular clouds and suggest that the observed filamentary structure is directly related to the formation of prestellar cores. Herschel observations now demonstrate that filaments are truly ubiquitous in the cold ISM. Palmeirim et al. (2013) have made an attempt to prepare an analytical model for an idealized cylindrical filament. According their model, filaments will have a dense, flat inner portion and show power law behaviour at the larger radii. They assumed the Plummer-like function (Nutter et al. 2008; Arzoumanian et al. 2011) for the density profile,

$\rho_{p}(r)=\rho_{\mathrm{c}} /\left[1+\left(r / R_{\mathrm{flat}}\right)^{2}\right]^{p / 2} \rightarrow N(r)=A_{p} \frac{\rho_{\mathrm{c}} R_{\mathrm{flat}}}{\left[1+\left(r / R_{\mathrm{flat}}\right)^{2}\right]^{(p-1) / 2}} /$,

where, $\rho_{\mathrm{c}}$ is the central density, $R_{\text {flat }}$ is the size of the flat inner part, parameter $p$ defines the steepness of the profile in the outer part, $A_{p}$ is a finite factor that controls the filament's inclination angle to the plane of sky. According to Ostriker (1964), the density structure of an isothermal gas cylinder in hydrostatic equilibrium could follow the above equation with $p=4$. In order to start with a simple realistic physical condition for TMC-1 cloud, we considered different regions of the cloud possessing different values of visual extinction parameter $\left(A_{V}\right)$. Lee et al. (1996) assumed a static, plane-parallel, semi-infinite cloud with a constant temperature $30 \mathrm{~K}$ and a density profile to mimic the condition of a self-gravitating isothermal sphere. The following relation was considered by them:

$n_{\mathrm{H}}=n_{\mathrm{H}} 0 /\left(1-c r / r_{\max }\right)^{2}$,

where $n_{\mathrm{H}}=n(\mathrm{H})+2 n\left(\mathrm{H}_{2}\right)$ is the number density of the hydrogen nuclei in the units of $\mathrm{cm}^{-3}, n_{\mathrm{H} 0}$ is the cloud density at the cloud surface, $n_{\mathrm{H} \max }$ the maximum number density, $r_{\max }$ the maximum cloud depth, $n_{\mathrm{H}} 0$ the hydrogen density at the cloud surface $(r=0)$, and $\mathrm{c}$ a constant. By evaluating the constant $\mathrm{c}$,

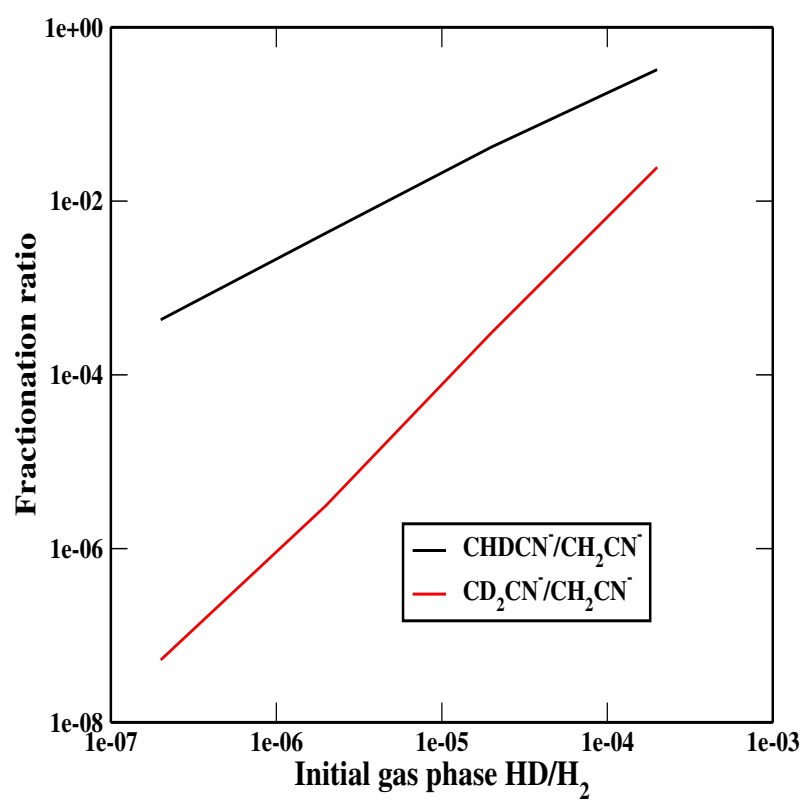

Fig. A.2. Variation of fractionation ratio of $\mathrm{CH}_{2} \mathrm{CN}^{-}$with the initial gas phase fractionation ratio (abundance of $\mathrm{HD} /$ abundance of $\mathrm{H}_{2}$ ).

they derived the following relationship between the hydrogen number density and the visual extinction parameter:

$n_{\mathrm{H}}=n_{\mathrm{H} 0}\left[1+\left[\left(\left(\frac{n_{\mathrm{H} \max }}{n_{\mathrm{H} 0}}\right)^{1 / 2}-1\right) \frac{A_{v}}{A_{v \max }}\right]\right]^{2}$,

where $A_{V \max }$ is the maximum visual extinction considered very deep inside the cloud. Lee et al. (1996) considered the above relationship for $T=30 \mathrm{~K}, n_{\mathrm{H} 0}=1 \times 10^{2} \mathrm{~cm}^{-3}, n_{\mathrm{H} \max }=1.042 \times$ $10^{4} \mathrm{~cm}^{-3}$, and $A_{V \max }=10.86$. As in Das \& Chakrabarti (2011), we assume that this relationship also holds for $T=10 \mathrm{~K}$. Values of $n_{\mathrm{H} 0}, n_{\mathrm{H} \max }$, and $A_{V_{\max }}$ are assumed to be similar to the values assumed by Lee et al. (1996).

In Fig. A.1.(a-f), we show the chemical evolution of different forms of cyanomethyl radical and some of its related molecules. We considered $A_{V}=10$, which corresponds to a hydrogen number density of $\left(n_{\mathrm{H}}\right)=8984.52 \mathrm{~cm}^{-3}$. Due to the huge abundances of hydrogenated species, abundances of any interstellar species are normally described with respect to the total number of hydrogen or with respect to the hydrogen molecule. In our case, we have presented the chemical abundances with respect to the total hydrogen nuclei in all forms. From the past observations, it is now known that water, methanol and carbon-dioxide are the major constituents of the interstellar grain mantle. According to Tielens et al. (1991), the abundance of water around the dense cloud region in the ice phase is $\sim 10^{-4}$, and according to Das et al. (2010) and references therein, abundances of $\mathrm{CO}_{2}$ and methanol in the ice phase could vary between $5-20 \%$ and $2-30 \%$, respectively, with respect to the solid state water. These huge abundances could be manifested in the gas phase through some interstellar energetic events. Recent observational facility, such as the Atacama Large Millimeter/submillimeter Array (ALMA) could be very useful for the confirmed detection of the interstellar complex species having magnitudes $\sim 10^{10}$ times lower than the water molecules. Most of the molecules in Fig. A.1 attain a peak value near $\sim 10^{5}$ years. In Fig. A.1.a, different forms of neutral $\mathrm{CH}_{2} \mathrm{CN}$ are shown, and it is evident that all the deuterated forms of $\mathrm{CH}_{2} \mathrm{CN}$ are reasonably abundant (peak abundance $>10^{-14}$ with respect to $n_{\mathrm{H}}$ ). In Fig. A.1.b, the chemical evolution of $\mathrm{CH}_{2} \mathrm{CN}^{-}$and its two deuterated isotopomers are shown. 
Table A.3. Comparison of fractional abundances with other observations/models.

\begin{tabular}{lccc}
\hline \hline Species & $\begin{array}{c}\text { Fractional abundance } \\
\text { by observations/other } \\
\text { chemical models }\end{array}$ & \multicolumn{2}{c}{$\begin{array}{c}\text { Fractional abundance } \\
\text { by our model }\end{array}$} \\
\cline { 3 - 4 } & $2.5 \times 10^{-09 O}, 4.59 \times 10^{-11 W}$ & $1.46 \times 10^{-09}$ & Abundance after $2 \times 10^{6}$ year \\
\hline $\mathrm{CH}_{2} \mathrm{CN}$ & $5.00 \times 10^{-100}, 6.95 \times 10^{-12 W}$ & $5.01 \times 10^{-09}$ & $3.43 \times 10^{-11}$ \\
$\mathrm{CH}_{3} \mathrm{CN}$ & $1.00 \times 10^{-080}, 2.95 \times 10^{-9} \mathrm{~W}$ & $4.93 \times 10^{-08}$ & $9.01 \times 10^{-10}$ \\
$\mathrm{HCN}$ & $1.02 \times 10^{-18 W}$ & $6.24 \times 10^{-16}$ & $3.49 \times 10^{-19}$ \\
$\mathrm{CH}_{3} \mathrm{CN}^{+}$ & $2.55 \times 10^{-14 W}$ & $2.78 \times 10^{-10}$ & $5.36 \times 10^{-17}$ \\
$\mathrm{CH}_{3} \mathrm{CNH}^{+}$ & $2.1-3.7 \times 10^{-10 T}$ & $1.38 \times 10^{-07}$ & $2.69 \times 10^{-10}$ \\
$\mathrm{DCN}$ & & & \\
\hline
\end{tabular}

Notes. ${ }^{(O)}$ Observation by Ohishi et al. (1992) in TMC-1. ${ }^{(W)}$ Chemical model by Woodall et al. (2007), by considering $n_{\mathrm{H}}=2 \times 10^{4} \mathrm{~cm}^{-3}$, $T=10 \mathrm{~K}, A_{V}=15 .{ }^{(T)}$ Observation by Turner (2001) in TMC-1. ${ }^{(C)}$ Our model by considering $n_{\mathrm{H}}=8984.52 \mathrm{~cm}^{-3}, T=10 \mathrm{~K}, A_{V}=10$.

Table A.4. Column densities of various forms of $\mathrm{CH}_{2} \mathrm{CN}$ and its related molecules around different regions of the ISM.

\begin{tabular}{|c|c|c|c|c|}
\hline Species & Isotopomers & $\begin{array}{c}\mathrm{AV}_{1} \\
\left(n_{\mathrm{H}}=341.46 \mathrm{~cm}^{-3}\right)\end{array}$ & $\begin{array}{c}\mathrm{AV}_{5} \\
\left(n_{\mathrm{H}}=2745.07 \mathrm{~cm}^{-3}\right)\end{array}$ & $\begin{array}{c}\mathrm{AV}_{10} \\
\left(n_{\mathrm{H}}=8984.52 \mathrm{~cm}^{-3}\right)\end{array}$ \\
\hline $\mathrm{CH}_{2} \mathrm{CN}$ & $\begin{array}{l}\mathrm{CH}_{2} \mathrm{CN} \\
\mathrm{CHDCN} \\
\mathrm{CD}_{2} \mathrm{CN}\end{array}$ & $\begin{array}{c}2.11 \times 10^{07} \\
8.76 \times 10^{02} \\
4.69 \times 10^{-02}\end{array}$ & $\begin{array}{l}1.10 \times 10^{13} \\
4.95 \times 10^{11} \\
3.89 \times 10^{09}\end{array}$ & $\begin{array}{l}2.33 \times 10^{13} \\
1.21 \times 10^{12} \\
1.44 \times 10^{10}\end{array}$ \\
\hline $\mathrm{CH}_{2} \mathrm{CN}^{-}$ & $\begin{array}{l}\mathrm{CH}_{2} \mathrm{CN}^{-} \\
\mathrm{CHDCN}^{-} \\
\mathrm{CD}_{2} \mathrm{CN}^{-}\end{array}$ & $\begin{array}{c}3.52 \times 10^{07} \\
1.46 \times 10^{03} \\
7.85 \times 10^{-02} \\
\end{array}$ & $\begin{array}{l}4.35 \times 10^{13} \\
1.04 \times 10^{12} \\
6.03 \times 10^{09}\end{array}$ & $\begin{array}{l}4.91 \times 10^{13} \\
9.43 \times 10^{11} \\
5.99 \times 10^{09}\end{array}$ \\
\hline $\mathrm{CH}_{2} \mathrm{CN}^{+}$ & $\begin{array}{l}\mathrm{CH}_{2} \mathrm{CN}^{+} \\
\mathrm{CHDCN}^{+} \\
\mathrm{CD}_{2} \mathrm{CN}^{+}\end{array}$ & $\begin{array}{c}2.76 \times 10^{04} \\
1.99 \times 10^{01} \\
1.05 \times 10^{-03}\end{array}$ & $\begin{array}{l}.42 \times 10^{11} \\
1.09 \times 10^{11} \\
9.88 \times 10^{08}\end{array}$ & $\begin{array}{l}4.67 \times 10^{12} \\
2.34 \times 10^{12} \\
2.56 \times 10^{10}\end{array}$ \\
\hline $\mathrm{CH}_{3} \mathrm{CN}$ & $\begin{array}{c}\mathrm{CH}_{3} \mathrm{CN} \\
\mathrm{CH}_{2} \mathrm{DCN} \\
\mathrm{CHD}_{2} \mathrm{CN}\end{array}$ & $\begin{array}{l}1.38 \times 10^{05} \\
9.42 \times 10^{01} \\
5.05 \times 10^{-03}\end{array}$ & $\begin{array}{l}.59 \times 10^{13} \\
6.81 \times 10^{11} \\
5.12 \times 10^{09}\end{array}$ & $\begin{array}{l}8.02 \times 10^{13} \\
1.64 \times 10^{12} \\
1.81 \times 10^{10}\end{array}$ \\
\hline $\mathrm{CH}_{3} \mathrm{CN}^{+}$ & $\begin{array}{c}\mathrm{CH}_{3} \mathrm{CN}^{+} \\
\mathrm{CH}_{2} \mathrm{DCN}^{+} \\
\mathrm{CHD}_{2} \mathrm{CN}^{+} \\
\end{array}$ & $\begin{array}{l}4.67 \times 10^{02} \\
1.73 \times 10^{-02} \\
9.58 \times 10^{-07} \\
\end{array}$ & $\begin{array}{l}4.08 \times 10^{06} \\
3.03 \times 10^{05} \\
2.43 \times 10^{03} \\
\end{array}$ & $\begin{array}{l}9.99 \times 10^{06} \\
2.49 \times 10^{05} \\
5.00 \times 10^{03} \\
\end{array}$ \\
\hline $\mathrm{CH}_{3} \mathrm{CNH}^{+}$ & $\begin{array}{c}\mathrm{CH}_{3} \mathrm{CNH}^{+} \\
\mathrm{CHDCNH}^{+} \\
\mathrm{CD}_{3} \mathrm{CNH}^{+} \\
\end{array}$ & $\begin{array}{c}4.28 \times 10^{03} \\
2.31 \times 10^{00} \\
1.24 \times 10^{-04} \\
\end{array}$ & $\begin{array}{l}3.31 \times 10^{11} \\
2.27 \times 10^{10} \\
2.24 \times 10^{08} \\
\end{array}$ & $\begin{array}{l}4.44 \times 10^{12} \\
3.18 \times 10^{11} \\
4.10 \times 10^{09}\end{array}$ \\
\hline $\mathrm{HCN}$ & $\begin{array}{l}\mathrm{HCN} \\
\mathrm{DCN}\end{array}$ & $\begin{array}{l}5.66 \times 10^{10} \\
2.23 \times 10^{12}\end{array}$ & $\begin{array}{l}6.09 \times 10^{14} \\
2.61 \times 10^{15}\end{array}$ & $\begin{array}{l}7.88 \times 10^{14} \\
2.20 \times 10^{15}\end{array}$ \\
\hline
\end{tabular}

Different forms of these molecules are also reasonably abundant (peak abundances $>10^{-13}$ with respect to $n_{\mathrm{H}}$ ). The chemical evolution of $\mathrm{CH}_{2} \mathrm{CN}^{+}$and two of its deuterated isotopomers are shown in Fig. A.1.c. Deuterated isotopomers of $\mathrm{CH}_{2} \mathrm{CN}^{+}$are not very abundant (peak abundances $>10^{-15}$ with respect to $n_{\mathrm{H}}$ ). In Fig. A.1.d, the chemical evolution of $\mathrm{CH}_{3} \mathrm{CN}$ along with its two deuterated isotopomers and chemical evolution of $\mathrm{HCN}$ and DCN are shown. All of them are found to be abundant (peak abundances $>10^{-13}$ with respect to $n_{\mathrm{H}}$ ). Chemical evolution of $\mathrm{CH}_{3} \mathrm{CN}^{+}$along with its two deuterated isotopomers are shown in Fig. A.1.e. Abundances of these species are several orders lower than the present observational limit. Figure A.1.f shows the chemical evolutions of $\mathrm{CH}_{3} \mathrm{CNH}^{+}$ion and its two deuterated isotopomers. Deuterated isotopomers of this ion are not very abundant. In brief, from Fig. A.1, it is evident that various forms of $\mathrm{CH}_{2} \mathrm{CN}^{-}$are reasonably abundant and could be observed with the present observational facility. In order to justify our modeling results, in Table A.3, we have compared our calculated abundances of some related species of the cyanomethyl anions with the existing theoretical/observational results.
In Table A.4, we have presented peak column densities of all the species for $A_{V}=1\left(n_{\mathrm{H}}=341.46 \mathrm{~cm}^{-3}\right), 5\left(n_{\mathrm{H}}=\right.$ $\left.2745.07 \mathrm{~cm}^{-3}\right)$ and $10\left(n_{\mathrm{H}}=8984.52 \mathrm{~cm}^{-3}\right)$. Column densities of the species are computed by following the relationship developed by Shalabiea et al. (1994):

$N(A)=n_{\mathrm{H}} x_{i} R$,

where $n_{\mathrm{H}}$ is the total hydrogen number density, $x_{i}$ the abundance of the $i$ th species, and $R$ the path length along the line of sight $\left(=\frac{1.6 \times 10^{21} \times A_{V}}{n_{\mathrm{H}}}\right)$. From Table A.4, it is evident that the column density of all the species are increasing linear up to the intermediate region $\left(A_{V}=5\right.$ and $\left.n_{\mathrm{H}}=2745.07 \mathrm{~cm}^{-3}\right)$ of the cloud, and beyond that the column density of all the species increases very slowly. From Table A.4, it is evident that $\mathrm{CH}_{2} \mathrm{CN}^{-}$, along with its deuterated isotopomers is the most abundant and that it requires detailed spectral studies to observe them in or around ISMs.

Despite the low elemental $\mathrm{D} / \mathrm{H}$ ratio $\left(\sim 10^{-5}\right.$, Linsky et al. 1995), several molecules in the ISM are found to be heavily fractionated. In our simulation, we varied the initial fractionation ratio to check the fractionation of $\mathrm{CH}_{2} \mathrm{CN}^{-}$. To mimic the 
physical condition, we considered $A_{V}=10, n_{\mathrm{H}}=8984.52 \mathrm{~cm}^{-3}$ and $T=10 \mathrm{~K}$ for this case. Fractionation ratio of the $\mathrm{CH}_{2} \mathrm{CN}^{-}$ attain a peak value near the intermediate time scale. In Fig. A2, only the peak values of the fractionation ratio are shown for different initial fractionation ratios. We also checked the fractionation ratios for $\mathrm{CH}_{2} \mathrm{CN}$ and $\mathrm{CH}_{2} \mathrm{CN}^{+}$and found that they behave in the same way as $\mathrm{CH}_{2} \mathrm{CN}^{-}$. Fractionation values are also very similar. It is interesting to note that the fractionation ratio for the singly deuterated cyanomethyl anion often crosses the elemental $\mathrm{D} / \mathrm{H}$ ratio. For the doubly deuterated isotopomer, the fractionation ratio crosses the elemental $\mathrm{D} / \mathrm{H}$ ratio for an initial fractionation ratio $>10^{-5}$.

\section{References}

Agundez, M., Fonfria, J. P., Cernicharo, J., Pardo, J. R., \& Guelin, M. 2008, A\&A, 479, 493

Allen, M., \& Robinson, G. W. 1977, ApJ, 212, 396 146, 227

Albertsson, T., Semenov, D. A., Vasyunin, A. I., Henning, T., \& Herbst, E. 2013, APJS, 207, 27

Arzoumanian, D., Andr, P., Didelon, P., et al. 2011, A\&A, 529, L6

Becke, A. D. 1993, J. Chem. Phys., 98, 5648

Chakrabarti, S., \& Chakrabarti, S. K. 2000a, A\&A, 354, L6

Chakrabarti, S. K., \& Chakrabarti, S. 2000b, Ind. J. Phys., 74B, 97

Chakrabarti, S. K., Das, A., Acharyya, K., \& Chakrabarti, S. 2006a, A\&A, 457, 167

Chakrabarti, S. K., Das, A., Acharyya, K., \& Chakrabarti, S. 2006b, BASI, 34, 299

Churchwell, E. 1980, ApJ, 240, 811

Clouthier, D. J., \& Moule, D. C. 1987, J. Am. Chem. Soc., 109, 6259

Cordiner, M. A., \& Sarre, P. J. 2007, A\&A, 472, 537

Cuppen, H. M., \& Herbst, E. 2007, APJ, 668, 294

Cuppen, H. M., Van Dishoeck E. F., Herbst, E., \& Tielens, A. G. G. M. 2009, A\&A, 508, 275

Cummins, S. E., Line, R. A., \& Thaddeus, P. 1986, APJS, 60, 819

Das, A., \& Chakrabarti, S. K. 2011, MNRAS, 418, 545

Das, A., Chakrabarti, S. K., Acharyya K., \& Chakrabarti, S. 2008a, New Astron., 13,457

Das, A., Acharyya, K., Chakrabarti, S. \& Chakrabarti, S. K. 2008b, A\&A, 486, 209

Das, A., Acharyya, K. \& Chakrabarti, S. K. 2010, MNRAS, 409, 789

Das, A. Majumdar, L., Chakrabarti, S. K., \& Chakrabarti, S. 2013a, New Astron., 23,118

Das, A. Majumdar, L., Chakrabarti, S. K., Saha, R., \& Chakrabarti, S. 2013b, MNRAS, 433, 3152

Demyk, K., Dartois, E., d'Hendecourt, L., et al. 1998, A\&A, 339, 553

Fortenberry, R. C., \& Crawford, T. D. 2011 a, J. Chem. Phys., 134, 154304

Fortenberry, R. C., \& Crawford, T. D. 2011b, Annu. Rep. Comput. Chem., 7, 195

Fortenberry, R. C., \& Crawford, T. D. 2011c, JPCA, 115, 8119

Fortenberry, R. C., Huang, X., Francisco, J. S., Crawford, T. D., \& Lee, T. J. 2012a, J. Phys. Chem. A, 116, 9582

Fortenberry, R. C., Huang, X., Francisco, J. S., Crawford, T. D., \& Lee, T. J. 2012b, J. Chem. Phys., 136, 234309

Fortenberry, R. C. Crawford, T. D., \& Lee, J. T. 2013, ApJ, 762, 121

Frisch, M. J., Trucks, G. W., Schlegel, H. B., et al. 2009, Gaussian 09, Revision D.01, D. J. Gaussian, Inc., Wallingford CT

Gerin, M., Combes, F., Encrenaz, P., et al. 1989, A\&A, 224, L24

Gibb, E. L., Whittet, D. C. B., Schutte, W. A., et al. 2000, ApJ, 536, 347

Goldsmith, P. F., Heyer, M., Narayanan, G., et al. 2008, ApJ, 680, 428
Hasegawa, T., \& Herbst, E. 1993, MNRAS, 261, 83

Hasegawa, T., Herbst, E., \& Leung, C. M. 1992, APJ, 82, 167

Herbig, G. H. 1995, Annu. Rev. Astophys., 33, 19

Herbst, E. 1985, ApJ, 291, 226

Herbst, E. 2001, Chem. Soc. Rev., 30, 168

Herbst, E. 2006, in Springer Handbook of Atomic, Molecular, and Optical Physics, ed. G. W. F. Drake (New York: Springer), 561

Huang, X., \& Lee, T. J. 2008, J. Chem. Phys., 129, 044312

Huang, X., \& Lee, T. J. 2009, J. Chem. Phys., 131, 104301

Huang, X., \& Lee, T. J. 2011, ApJ, 736, 33

Hudson, R. L., Moore, M. H., \& Gerakines, P. A. 2001, ApJ, 550, 1140

Inostroza, N., Huang, X., \& Lee, T. J. 2011, J. Chem. Phys., 135, 244310

Irvine, W. M., Friberg, P., Hjalmarson, A., et al. 1988, ApJ, 334, L107

Lee, C., Yang, W., \& Parr, R. G. 1988, Phys. Rev. B, 58, 785

Lee, H. H., Herbst, E., Pineau des Forets, G., Roueff, E., \& Le Bourlot, J. 1996 A\&A, 311, 690

Leitch-Devlin, M., A., \& Williams, D. A. 2013, MNRAS, 1985, 295

Linsky, J. L., Diplas, A., Wood, B. E., et al. 1995. ApJ. 451, 335

Lykke, K. R., Neumark, D. M., Andersen, T., Trapa, V. J., \& Lineberger, W. C. 1987, J. Chem. Phys., 87, 6842

Majumdar, L., Das, A., Chakrabarti, S. K., \& Chakrabarti, S. 2012, Res. Astron. Astrophys., 12, 1613

Majumdar, L., Das, A., Chakrabarti, S. K., \& Chakrabarti, S. 2013, New Astron., 20, 15

McElroy, D., Walsh, C., Markwick, A. J., et al. 2013, A\&A, 550, A36

Novozamsky, J. H., Schutte, W. A., \& Keane, J. V. 2001, A\&A, 379, 588

Nutter, D., Kirk, J. M., Stamatellos, D., \& Ward-Thompson, D. 2008, MNRAS, 384, 755

Ohishi, M., Irvine, W. M., \& Kaifu, N. 1992, IAU Symp., 150, 1710

Ostriker, J. 1964, ApJ, 140, 1056

Ozeki, H., Hirao, T., Saito, S., \& Yamamoto, S. 2004, ApJ, 617, 680

Park, J. Y., \& Woon, D. E. 2006, ApJ, 648, 1285

Palmeirim, P., Andre, Ph., Kirk, J., et al. 2013, A\&A, 550, A38

Pascual-Ahuir, J. L., Silla, E., \& Tun, I. 1994, J. Comp. Chem., 15, 1127

Person, W. B., \& Kubulat, K. 1990, J. Mol. Struc., 224, 225

Pickett, H. M. 1991, J. Mol. Spectrosc., 148, 371

Pilbratt, G. L., Riedinger, J. R., Passvogel, T., et al. 2010, A\&A, 518, L1

Prasad, S. S., \& Huntress Jr., W. T. 1980, ApJS, 43, 1

Roberts, H., \& Millar, T. J. 2000, A\&A, 361, 388

Sarre, P. J. 2000, MNRAS, 313, L14

Sarre, P. J. 2006, J. Mol. Spec., 238, 1

Schutte, W. A., \& Greenberg, J. M. 1997, A\&A, 317, L43

Schutte, W. A., Greenberg, J. M., van Dishoeck, E. F., et al. 1997, Ap\&SS, 255, 61

Schutte, W. A., Boogert, A. C. A., Tielens, A. G. G. M., et al. 1999, A\&A, 343, 966

Shalabiea, O. M., \& Greenberg, J. M. 1994, A\&A, 290, 266

Stantcheva, T., Shematovich, V. I., \& Herbst, E. 2002, A\&A, 391, 1069

Soifer, B. T., Puetter, R. C., Russell, R. W., et al. 1979, ApJ, 232, L53

Schneider, S., \& Elmegreen, B. G. 1979, ApJS, 41, 87

Smith, I. W. M., Herbst, E., \& Chang, Q. 2004, MNRAS, 350

Su, T., \& Chesnavich, W. J. 1982, J. Chem. Phys., 76, 5183

Tielens, A. G. G. M., Tokunaga, A. T., Geballe, T. R., \& Baas, F. 1991, ApJ, 381, 181

Tomasi, J., Mennucci, B., \& Cancs, E. 1999, J. Mol. Struct. (Theochem), 464, 211

Tomasi, J., Cammi, R., Mennucci, B., Cappelli, C., \& Corni, S. 2002, Phys. Chem. Chem. Phys., 4, 5697

Tomasi, J., Mennucci, B., \& Cammi, R. 2005, Chem. Rev., 105, 2999

Turner, B. E. 2001, ApJS, 136, 579

Woodall, J., Agndez, M., Markwick-Kemper, A. J., \& Millar, T. J. 2007, A\&A, 466, 1197

Woon, D. E., \& Herbst, E. 2009, APJS, 185, 273 